Discussion Paper No. 14-075

Improving Voluntary Public Good Provision by a Non-Governmental, Endogenous Matching Mechanism: Experimental Evidence

Christiane Reif, Dirk Rübbelke, and Andreas Löschel

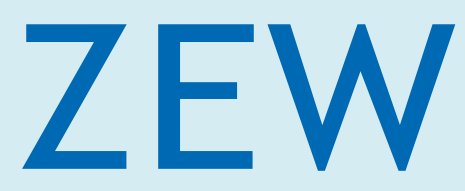

Zentrum für Europäische Wirtschaftsforschung $\mathrm{GmbH}$ Centre for European Economic Research 
Discussion Paper No. 14-075

\section{Improving Voluntary Public Good Provision by a Non-Governmental, Endogenous Matching Mechanism: Experimental Evidence}

Christiane Reif, Dirk Rübbelke, and Andreas Löschel

Download this ZEW Discussion Paper from our ftp server:

http://ftp.zew.de/pub/zew-docs/dp/dp14075.pdf

Die Discussion Papers dienen einer möglichst schnellen Verbreitung von neueren Forschungsarbeiten des ZEW. Die Beiträge liegen in alleiniger Verantwortung der Autoren und stellen nicht notwendigerweise die Meinung des ZEW dar.

Discussion Papers are intended to make results of ZEW research promptly available to other economists in order to encourage discussion and suggestions for revisions. The authors are solely responsible for the contents which do not necessarily represent the opinion of the ZEW. 


\title{
Improving voluntary public good provision by a non-governmental, endogenous matching mechanism: experimental evidence
}

\author{
Christiane Reif $^{\mathrm{a}}$, Dirk Rübbelke ${ }^{\mathrm{b}}$, Andreas Löschel $^{\mathrm{c}}$
}

\begin{abstract}
Social norms can help to foster cooperation and to overcome the free-rider problem in private provision of public goods. This paper focuses on the enforcement of social norms by a selfintroduced punishment and reward scheme. We analyse if subjects achieve to implement a normenforcement mechanism at their own expense by applying the theory of non-governmental normenforcement by Buchholz et al. (2014) in a laboratory experiment. Based on their theory without central authority and endogenously determined enforcement mechanism, we implement a twostage public good game: At the first stage subjects determine the strength of penalty/reward on their own and in the second stage they decide on their contributions to the public good. We find that the mechanism by Buchholz et al. (2014) leads to a higher public good contribution than without the use of any mechanism. Only in a few cases groups end up with a zero enforcement mechanism. This result indicates that subjects are apparently willing to contribute funds for implementing an enforcement mechanism. Moreover, higher enforcement parameters lead to higher public good contributions in the second stage, although too high enforcement parameters lead to unreachable theoretical optima.
\end{abstract}

JEL Code: H41, C92

Keywords: laboratory experiment, public good, matching mechanism, social norms, norm enforcement

Acknowledgments: Financial support by the German Federal Ministry of Education and Research (FKZ 01UN1016A) and the Deutsche Forschungsgemeinschaft (DFG, grant no. SFB504) for the experimental laboratory University Mannheim is gratefully acknowledged. We thank Jürgen Bracht, Josef Falkinger, and Simon Gächter for the kind provision of their experimental instructions. We are also indebted to the participants of seminars and conferences held in Bilbao, Istanbul, Kiel, Mannheim, and Oxford for helpful comments. Part of the research was conducted during a research stay at the Basque Centre for Climate Change (BC3). We thank the Institute for its hospitality. We thank Carlo Gallier for his support.

\footnotetext{
${ }^{a}$ Correspondence: Christiane Reif, Centre for European Economic Research (ZEW), L7,1, 68161 Mannheim, Germany, reif@zew.de

b Professor Dr. Dirk Rübbelke, Technische Universität Bergakademie Freiberg, Germany, dirk.ruebbelke@vwl.tu-freiberg.de

c Professor Dr. Andreas Löschel, Westfälische Wilhelms-University Münster, Münster, Germany, and Centre for European Economic Research (ZEW), loeschel@uni-muenster.de
} 


\section{Introduction}

Although cooperative behaviour in social dilemmas is observable (e.g. charitable giving, voting, recycling), the incentives for free-riding are still high for individuals. Therefore, the analyses of the private provision of public goods and its free-rider problem have a long theoretical and experimental tradition (e.g. Cornes and Sandler 1985, Bergstrom et al. 1986). ${ }^{1}$ Despite research in sociology and psychology also in economic science attention has shifted to social norms. These norms can help to overcome the free-rider problem and are one of the key factors for cooperation (Voss 2001, p 110, Fehr and Fischbacher 2004a). Social norms are in general shared standards of how to behave appropriately in specific situations (see e.g. Horne 2001, Ellickson 2001, Voss 2001, Fehr and Fischbacher 2004a). This paper focuses on the enforcement of social norms by punishment and reward schemes and leaves aside the evolutionary dynamics of social norms discussed by other researchers (see e.g. Axelrod 1986, Sethi and Somanathan 1996, Ostrom 2000, Azar 2004).

The aim of this paper is to analyse whether subjects achieve to implement a norm-enforcement mechanism on their own costs to impose the provision of public goods. Therefore, we conduct a laboratory experiment based on the theory by Buchholz et al. (2014). In this theory the strength of a non-governmental enforcement mechanism is endogenously determined by the subjects themselves. At this model's first stage individuals decide on their contributions to finance an enforcement mechanism. At the second stage they decide on their contributions to the public good based on the established enforcement mechanism. The underlying social norm itself is taken as given and is determined by the average contribution to the public good. Deviations from this standard are punished or rewarded. Different to third party punishment approaches (e.g. Fehr and Gächter 2000, Fehr et al. 2002, Fehr and Fischbacher 2004a, 2004b), this sanctioning mechanism is endogenously implemented by the actors themselves and before the subjects decide on their public good contributions in the second stage. ${ }^{2}$ So the subjects have to solve a two-fold public good problem: contributing to the enforcement mechanism and contributing to the public good.

Furthermore, the non-governmental norm enforcement mechanism by Buchholz et al. (2014) contributes also to the research on matching mechanisms, which are possible instruments to strengthen cooperation in social dilemmas. Matching mechanisms are strongly related to social norms because the individual provision depends on the others' provision of public goods, which shows conditional cooperation and adhering social norms in subjects' social environment (Guttman 2013). Theoretically, matching mechanisms 'manipulate' the effective price of a public good to incentivise the voluntary public good provision. Mechanisms with or without a central role of the government can be distinguished and there is a broad range of applications for matching schemes (Buchholz et al. 2011).

Among the related experimental literature on matching behaviour without central authority is a laboratory experiment by Guttman (1986) based on the theory by Guttman (1978) in which the conditional cooperation increases the public good provision at lower costs. In this repeated public goods games experiment subjects contribute in the current round to the public good conditionally on

\footnotetext{
${ }^{1}$ Also see Löschel and Rübbelke (2014) discussing voluntary provision and undersupply of public goods in an international context.

${ }^{2}$ For an approach with endogenously determined intensity of the social norm, see Lindbeck et al. (1999). Mengel (2008) provides another approach endogenizing the strength of the norm, defined as rising number of agents internalizing the social norm in a prisoners' dilemma interaction model.
} 
the other group members' previous contributions. This implicit matching leads to higher contribution levels compared to unconditional settings with individually provided public goods. Moreover, these conditional contributions are higher for subjects with a higher marginal payoff from the public good provision. Furthermore, Andreoni and Varian (1999) implement the mechanism by Guttman (1978, 1987) as binding offers of side payments by one individual to another at the first stage and the decision on cooperation at the second stage in a prisoners' dilemma experiment. They find that the mechanism supports cooperation and the Pareto efficient outcome is achieved. However, decentralized mechanisms are limited when the group size is large because the personal interaction of agents as driving factor for cooperation is difficult in larger groups (e.g. Buchholz et al. 2014).

The theory by Falkinger et al. (1996) on a centralized matching mechanism is tested in an experiment by Falkinger et al. (2000) with a subsidy-tax scheme, in which the government rewards or penalises deviations from the average public good provision. ${ }^{3}$ Their results show that the mean contributions are higher in the mechanism treatment. Bracht et al. (2008) compare the two mechanisms in a laboratory experiment: compensation mechanism by Guttman (1978) implemented as subsidizing contributions in a pre-stage and the Falkinger mechanism with centralized subsidy. The results show higher public good provision with both mechanisms compared to public good provision without any mechanisms. Concerning the predictions of the average level of contributions, the Falkinger mechanism performs better in their laboratory experiment. In contrast to the theory by Falkinger et al. (2000) which has an exogenous reward scheme, Buchholz et al. (2014) provide a theory without central authority and an endogenous norm-enforcement mechanism.

Schultz et al. (2007) and Alcott (2011) conduct field experiments closely related to the idea of social norms as non-governmental mechanism. In both field experiments the effect of descriptive and injunctive norms on subjects' energy conservation is analysed. In these non-price approaches Schultz et al. (2007) show that the initial levels of energy consumption have a crucial impact on the effect of descriptive norms leading to the so called boomerang effect, ${ }^{4}$ which can partly be absorbed by implementing an injunctive norm. Alcott (2011) finds that the effects of such norms conveyed via socalled 'home energy reports' are equivalent to an 11 to $20 \%$ short-run price increase.

In this paper we base our experiment on the theory by Buchholz et al. (2014) to evaluate the matching method and its suitability for coordinating the private provision of public goods. A twostage design in a non-governmental mechanism environment is analysed. In particular the endogenous determination of an enforcement mechanism has not been experimentally tested in this context and we analyse whether subjects are willing to implement such a mechanism. We apply a non-linear payoff function to design the theory of Buchholz et al. (2014) in the same way as in Falkinger et al. (2000) or Bracht et al. (2008). In our setting without a central authority and an endogenously determined punishment/reward scheme, we find higher public good provision with the mechanism. Furthermore, subjects initially fund the enforcement parameter. In particular, only in a few cases groups ended with a zero enforcement mechanism, which shows that subjects are willing to contribute funds for implementing an enforcement mechanism. Moreover, higher enforcement parameters lead to higher public good contributions in the second stage. The results

\footnotetext{
${ }^{3}$ Andreoni and Bergstrom (1996) also suggest an effective-price influencing mechanism involving a central authority. See Baker et al. (2009) who test different centralized matching mechanisms, either a lump-sum matching when reaching a threshold or one-to-one matching in a laboratory experiment.

${ }^{4}$ Households initially consuming less than the average use the descriptive norm as justification to consume more.
} 
are in line with previous experiments with matching mechanism, but additionally provide information on the endogenous establishment of an enforcement mechanism.

\section{Mechanism and Experimental Implementation}

\section{Mechanism}

The theory is based on the paper by Buchholz et al. (2014) on voluntary public good provision influenced by social norms in a setting without governmental intervention. As the authors show, the considered mechanism establishing and enforcing norms may be effective in overcoming free-rider problems even when facing voluntary public good provision in large societies.

The model simultaneously handles two voluntary provision problems in a two-stage game: At the first stage, individuals voluntarily contribute to finance an agency establishing and enforcing a norm. At the second stage, individuals - influenced by the norm and its enforcement by the agency - decide on their voluntary provision to the public good. The specific norm applied is the average contribution of all the other individuals to the public good, so the budget for rewarding and punishing is balanced (see also Falkinger et al. 2000).

This non-governmental norm enforcement mechanism is to a certain extent related to previous mechanisms with or without a central role for the government. Among the decentral mechanisms is the matching approach first suggested by Guttman (1978), in which the free-rider problem in public good provision is addressed in a setting comprised of two stages. At the first stage, individual agents stipulate their matching rates, i.e. conditional contributions to the public good made per unit of the other agents' public good provision. At the second stage, agents provide their contribution to the public good, which is not made conditionally on other agents' provision.

The paper by Falkinger (1996) provides a mechanism with a central authority's intervention. Here, at the first stage, the government decides on rates rewarding individual agents' contribution deviating from the other agents' average contribution to the public good. At the second stage, individual agents set their voluntary contributions to the public good, taking into account the rewarding rates, which are exogenous for them.

In contrast, in Buchholz et al. (2014), the non-governmental norm-enforcement mechanism's reward rate is influenced by the agents through their voluntary contributions at stage one of the game, i.e. by the level of funds channelled towards the norm-enforcing agency. Thus, the reward rates are not exogenous anymore. Secondly, in the Falkinger (1996) scheme there is no transaction cost associated with the government's activity. The endogenously determined norm-enforcement causes costs, which are covered by the subjects' donations at stage one. ${ }^{5}$

The norm-enforcement model includes a scenario in which the group financing the enforcement mechanism (first stage) and the target group (second stage) differ as well as a scenario in which both may coincide. We focus on the latter, which is also in line with Coleman's (1990) classification of a conjoint norm targeting and benefiting the same individuals.

\footnotetext{
${ }^{5}$ Please note that with altruistic punishment/reward (e.g. Fehr and Gächter 2002) or also endogenously determined punishment and reward schemes (see e.g. Ertan et al. 2009, Kosfeld et al. 2009) there is no decline of the effective price of the public good like in the matching approaches.
} 
In the specification of the general setting in Buchholz et al. (2014), a Cobb-Douglas utility function of the form

$$
U=c^{\alpha} G^{1-\alpha}
$$

is employed where $c$ is private consumption and $G$ total public good supply. Private consumption $c$ comprises the consumption of a private good $y$ and 'social esteem' $r$ generated through the normenforcement mechanism, i.e.

$$
c=y+r
$$

The public good $G$ is defined as

$$
G=\sum_{i=1}^{n} g_{i}
$$

Prices of the individual goods are set equal to unity. Then, the monetary income $I$ constraint reads as follows:

$$
I=c_{i}+g_{i}+e_{i}
$$

The reward $r$ is positive for those contributing more and negative for those contributing less than the average of all other agents. The reward can be specified as:

$$
r=\beta\left(g_{i}-\frac{G_{-i}}{(n-1)}\right)
$$

The deviation from the average is weighted by parameter $\beta$, which represents the strength of the sanctioning mechanism. This strength - in turn - depends on the amount of donations $E=\sum_{i=1}^{n} e_{i}$ collected by the agency at stage one of the game, with $\beta=\beta(E), \beta(0)=0, \beta(E)<1, \beta^{\prime}(E)>0$, and $\beta^{\prime \prime}(E)<0$.

By maximizing (1) subject to (4), we obtain the following FOC:

$$
M R S \equiv-\frac{\frac{d u}{d c}}{\frac{d u}{d G}}=1-\beta
$$

Equivalently to the exogenously fixed reward rate in Falkinger (1996), the effective price of public good provision is reduced by $\beta$ (see right-hand side of (6)). To put it differently, the FOCs in the norm-enforcement model (Buchholz et al. 2014) and in the tax-subsidy model by Falkinger (1996) are formally equivalent. Yet, the driving forces for the decline in the effective price differ. In the normenforcement model, the decline takes place via an increase in an agent's private consumption (augmentation of social esteem) by $\beta$ per unit of his public good provision. In Falkinger's tax-subsidy model, the respective agent receives a subsidy or conditional transfer of $\beta$ monetary units per unit of his public good provision.

As the FOCs are decisive for an agent's decision making and as these coincide in both models, we could consider either of both effective price reduction channels (monetary-subsidy payment or 
private-consumption 'grant') in our experimental analysis. ${ }^{6}$ It proved more feasible to employ the 'subsidy interpretation' in order to implement the norm-enforcement model by Buchholz et al. (2014) in an experimental setting. The specification of $\beta$ in Buchholz et al. (2014) is:

$$
\beta=1-\frac{1}{1+E n^{-\gamma}}
$$

The parameter $\gamma$ indicates the degree of rivalry in the use of funds available for the norm-enforcing agency. It is restricted to $\gamma \in[0,1]$, where zero stands for non-rivalry and one for full-rivalry. The degree of rivalry shows whether the norm could be enforced as a public good addressing all individuals equally or if the norm has to be enforced individually. We focus on non-rivalry in our experiment and therefore employ the following specification:

$$
\beta=1-\frac{1}{1+E}
$$

\section{Experimental Implementation}

In the context of social norms, the social esteem parameter $r$ can be interpreted as experience of guilt or shame related to so-called oughtness norms (Hechter and Opp 2001, p xiii). ${ }^{7}$ According to Hechter and Opp (2001), these types of norms are associated with moral obligations and subjects follow them no matter of the outcome. The theory by Buchholz et al. (2014) is specified for the experiment as 'subsidy interpretation' explained in the previous section. The social esteem parameter $r$ is monetized like subsidies and taxes in the tax-subsidy model by Falkinger (1996). It can be negative or positive depending on the own contribution compared to the average contribution to the public good by the other players in the group. In monetizing the social esteem parameter $r$, we transform the underlying norm to a regulatory norm with social expectations (Hechter and Opp 2001). Subjects not complying with the norm, by deviating from the average in our case, are punished.

Deviating from the common linear payoff structure with boundary equilibria, the predictions of the theory are based on a Cobb-Douglas utility function with interior solutions. ${ }^{8}$ Fitting the experimental design to the based theory, the payoff function has to fulfil an underlying Cobb-Douglas utility function and the budget constraint described in (4). Therefore we implement the individual nonlinear payoff function also used by Falkinger et al. (2000) and Bracht et al. (2008) based on Keser (1996):

$$
\pi_{i}=5 \cdot c_{i}-0.05 \cdot c_{i}^{2}+G
$$

\footnotetext{
${ }^{6}$ Please take into account that the nominal unit prices of the private and public goods are assumed to be equal to unity.

${ }^{7}$ Please see Rege (2008) for a model in which the social status signals subjects' non-observable abilities.

${ }^{8}$ Here we use an approach with interior solutions due to three main reasons: Firstly, to set up a design close to the underlying theory with a Cobb-Douglas utility function. Secondly, to compare our results with those papers closely related to ours by Falkinger et al. (2000) and Bracht et al. (2008), who also use a non-linear payoff function. Thirdly, to overcome limits of boundary equilibria where decision errors can only lead to overcontribution, but not to under-contribution (see e.g. Andreoni 1993, Ledyard 1995, Keser 1996, Sefton and Steinberg 1996). Furthermore, zero contributions can be seen as socially unacceptable (see Keser 1996). For further discussion on voluntary public goods provision with interior solutions please see Laury and Holt (2008).
} 
$G$ is the sum of the group's public good contributions (for a group of 3 subjects: $\sum_{i=1}^{3} g_{i}$ ). This means that individuals get paid the group's contributions from the public good. $c_{i}$ is the remaining private money for private consumption. In the mechanism treatment $c_{i}$ depends on the decisions in the first and second stage.

$$
c_{i}=I_{i}-e_{i}-g_{i}+\beta \cdot\left(g_{i}-\frac{G_{-i}}{2}\right)
$$

The subjects get an endowment $I_{i}$ with which they can decide on their contributions in the game. In the first stage they decide on the contribution to the enforcement mechanism $e_{i}$ and in the second stage on the public good provision $g_{i}$. The enforcement parameter $\beta$ results from summing up the group contributions $\left(E=\sum_{i=1}^{3} e_{i}\right.$ ) in the first stage and is calculated according to (8). The translation of the group investment $E$ to the enforcement agency into the strength of sanctioning is provided in a table based on the equation (8) for the participating subjects.

In the baseline treatment, $c_{i}$ reduces with only one stage and $\beta=0$ to:

$$
c_{i}=I_{i}-g_{i}
$$

The equilibria predictions for the enforcement parameter $\beta$ are based on the efficiency condition by Falkinger et al. (2000) with $\beta=1-(1 / n)$, resulting for a group of 3 subjects in $\beta^{*}=2 / 3$. Based on the payoff function (9) and (10), the equilibrium for the public good provision can be calculated with $g_{i}^{*}=-10 /(\beta-1)$. The following Table 1 provides the summary of our experimental design including the predicted interior equilibria.

Table 1: Summary of Experimental Design

\begin{tabular}{ccccccc}
\hline Treatment & $\begin{array}{c}\text { Group } \\
\text { size }\end{array}$ & $\begin{array}{c}\text { Endowment } \\
\text { per period }\end{array}$ & MRS & E & B & $\begin{array}{c}\text { Equilibria } \\
\text { prediction }\end{array}$ \\
\hline Baseline & 3 & 50 LD & 1 & - & - & $g^{B}=10$ \\
Mechanism & 3 & 50 LD & $1-\beta$ & 2 & $2 / 3^{*}$ & $g^{M}=30^{* *}$ \\
\hline
\end{tabular}

\section{Experimental Procedure}

The subjects were randomly assigned to treatments and groups of three anonymous players. Subjects played either the mechanism or the baseline treatment.

The mechanism treatment is a two-stage public good game based on the theory by Buchholz et al. (2014). The subjects are endowed with $€ 8$ (50 LD) and decide at the first stage on their contribution to a norm-enforcement mechanism. By endogenously funding the mechanism on their own cost, they establish a norm defined as average contribution.

Before subjects decide on their contribution to the public good at the second stage, they experience the sum of all contributions in the group, the average contribution to the institution of the first stage, the resulting enforcement parameter $\beta$, and their remaining money on their private accounts (see $z$ tree screenshots in the Appendix A5). At the second stage subjects contribute to the public good based on the resulting enforcement parameter $\beta$ of the first stage. Beside the subjects' decisions on public good contributions, they additionally tell their expectations of the other group members' 
average contribution to the public good in the second stage. After their decision they learn about the sum of the group contributions to the public good, the average contributions, the income of the other group members, and their own income distinguished by its origin (public good, private account, punishment/reward). All the information is anonymously provided and includes all previous periods (see z-tree screenshots in the Appendix A5).

Our control treatment labelled as baseline is a simple public good game without mechanism, which reduces the mechanisms treatment to a one-stage game $(\beta=0)$. In both treatments the one shot games were repeated 10 times (plus two practice periods at the beginning) to allow for learning effects in both cases and to illustrate recurrent social interaction.

\section{Experimental Protocol}

The experiment was run in the laboratory mLab at the University of Mannheim, Germany. Students were recruited via the recruitment software Orsee (Greiner 2004). Overall, 108 subjects participated, with 51 subjects in baseline and 57 subjects in the mechanism treatment. They got a $€ 4$ show up fee and could additionally earn money from the game. The experiment was conducted with the software z-tree (Fischbacher 2007). The subjects were randomly assigned to the treatments and in each session randomly assigned to a group of three players. They were instructed about the rules of the game with the help of a manuscript including the payoff function with numerical examples, and control questions to check the understanding of these instructions (see Appendix A4). We ensured that all subjects answered the entire control questions correctly before starting the experiment. The experiment included 2 practice and 10 payoff relevant periods. For both treatments they got an endowment of 50 laboratory dollar (LD) in each period. At the end of the experiment one round was randomly drawn for payment. The LDs were transferred in Euro with the rate 0.08 . The average earnings (excluding the show-up-fee) were €12.24 in baseline and €12.36 in the mechanism treatment. ${ }^{9}$ After the game the subjects answered a questionnaire on risk, trust, rules and sociodemographic aspects.

\section{Results}

Contributions on the individual level to the public good (at the second stage) are on average 12.81 (standard deviation 4.52) for baseline, and 27.45 (standard deviation 10.85) for the mechanism treatment, which reveals higher contribution levels but also larger variation in the mechanism treatment (see Table 2). In the baseline treatment a fraction of $50.78 \%$ of individuals contribute close (0-10\% deviation) to the equilibrium of $g^{B}=10$ with $48.43 \%$ exactly contributing the equilibrium. On average, subjects in the baseline treatment spend $25.62 \%$ of their endowment to the public good. In the mechanism treatment this fraction $\left(27 \leq g_{i}^{M} \leq 33\right)$ is only $13.15 \%$, which we attribute to the complex design. The most frequent contribution was $g_{i}^{M}=10$ with a fraction of $11.93 \%$ and $g_{i}^{M}=20$ with a fraction of $10.53 \%$. On average, subjects spend $54.94 \%$ of the initial endowment and

\footnotetext{
9 Please note that the payout period was randomly drawn. Looking at the potential payoffs, the average earnings in baseline are $€ 12.19$ with a standard deviation of 0.59 and $€ 12.46$ in the mechanism treatment with a standard deviation of 1.23 . The potential payoffs are significantly different $(p=0.0007$ Wilcoxon rank-sum test). The median of the potential earnings in baseline and mechanisms are significantly different from the earnings when reaching the equilibria (Wilcoxon singed rank test $p=0.0276$ for baseline and $p=0.0000$ for mechanism treatment).
} 
$58.08 \%$ of the remaining endowment to the public good in the second stage. The following Table 2 provides the summary statistics.

Table 2: Summary statistics*

\begin{tabular}{cccccc}
\hline & $\begin{array}{c}1^{\text {st }} \text { stage } \\
\text { contribution } \\
\text { to } \\
\text { mechanism }\end{array}$ & $\begin{array}{c}\text { min/max } \\
\text { group } \\
\text { contribution } \\
\text { to mechanism } \\
\text { in } 1^{\text {st }} \text { stage }\end{array}$ & Resulting B & $\begin{array}{c}\text { Group } \\
\text { contribution } \\
\text { PG }\end{array}$ & $\begin{array}{c}\text { min/max group } \\
\text { contribution }\end{array}$ \\
\hline Baseline & - & - & - & 12.81 & \\
Mechanism & 7.84 & $0 / 48$ & 0.76 & 27.47 & $9.22 / 16.22$ \\
\hline
\end{tabular}

*Only payoff relevant periods are included, not the two training periods at the beginning.

The individual decisions over the ten periods are not independent. Therefore, we base further analyses on group average. ${ }^{10}$ We focus on the treatment level and additionally provide details on single groups.

The contributions of the two treatments are significantly different from each other based on a Kruskal-Wallis test ( $p=0.0001$ ). Figure 1 shows the mean contributions of groups for the periods $1-10$ by treatment and their confidence intervals. The graph for baseline shows declining contributions over time, as other experimental studies of private public good provision have shown before (see e.g. Ledyard 1995 or in non-linear settings Keser 1996, Sefton and Steinberg 1996, Falkinger et al. 2000, Bracht et a. 2008). The contributions in baseline are above the equilibrium of $g^{B}=10$, except for the last period in which the group contributions fall below the theoretical equilibrium. Comparisons of the first and second half in the baseline treatment ( $p=0.0000$ Wilcoxon signed rank test), as well as the first and the last period ( $p=0.0000$ Wilcoxon signed rank test) show significant differences and provide evidence for an end round effect (e.g. Andreoni 1988, Laury and Holt 2008). The median of the group contributions differs significantly ( $p=0.0000$ median test) from the theoretical equilibrium of $g^{B}=10$. The average contribution over all periods in baseline is 12.81 with standard deviation of 2.13, revealing over-contribution. This result is in line with findings by Falkinger et al. (2000) and Bracht et al. (2008) with different group sizes (4 subjects and 2 subjects respectively).

In the mechanism treatment the contributions are higher than in baseline in all rounds. The difference is statistically significant ( $p=0.0000$ Mann-Whitney $U$ test). This is also true if we only compare the first half (period 1-5) or second half (period 6-10) of the treatments (both $p=0.0000$ Mann-Whitney $U$ test). Figure 1 shows rather increasing contributions over time than declining contribution behaviour. Tests comparing the first and second half of the mechanism treatment ( $p=0.0000$ Wilcoxon signed rank test) as well as a comparison of the first and the last round $(p=0.0000$ Wilcoxon signed rank test) in the mechanism treatment are significantly different. These results rather indicate a learning effect of the 10 payment relevant periods, which is in contrast to results by Falkinger et al. (2000) with exogenous parameter, where subjects played close to the equilibrium from the first periods onwards.

Although the second stage optimal contribution depends on the previously realized enforcement parameter $\left(\mathrm{g}_{\mathrm{i}}^{*}=-10 /(\beta-1)\right)$, we first compare the public good contribution to the theoretical equilibrium of $g^{M}=30$. This perspective enables us to relate our resulting provision levels with those of previous research with similar mechanisms, but exogenously given punishment parameters

\footnotetext{
${ }^{10}$ We base the tests on group average due to independency at this level (see Falkinger et al. 2000).
} 
by Falkinger et al. (2000) and Bracht et al. (2008). Furthermore, from a theoretical perspective, the subgame-perfect equilibria are solved by backward induction in which the second stage equilibrium is solved first.

If we assume the optimal behaviour in stage one, resulting in a $\beta^{*}=2 / 3$, the optimal contribution in equilibria would be $g^{M}=30$. All the mean contributions in the mechanism treatment are below or at this equilibrium. There is a significant difference between the $g^{M}=30$ equilibria and the actual median group contributions ( $p=0.0000$ median test). The average contribution over all periods is 27.45 with a standard deviation of 1.79 , indicating under-contribution. Although the public good is underprovided, on average the contributions in mechanism are closer to the theoretical equilibrium than in baseline.

We calculate the confidence intervals $(\mathrm{Cl})$ for the two treatments in the manner of Falkinger et al. (2000) and Bracht et al. (2008) by bootstrapping to provide deeper insight than the previous reported standard deviations. ${ }^{11}$ Figure 1 shows the resulting Cls for both treatments. The Cls of the treatments do not overlap in any round. The $\mathrm{Cl}$ for the mechanism treatment is wider compared to baseline, which shows a larger variation of contributions in mechanism. The $\mathrm{Cl}$ in baseline gets narrower in the end periods. In the mechanism treatment it is unchanged wide. The $\mathrm{Cl}$ in mechanism includes the equilibrium in far more periods than in baseline. This indicates that playing the equilibrium in mechanism cannot be rejected.

Figure 1: Mean contributions periods 1-10 per treatment

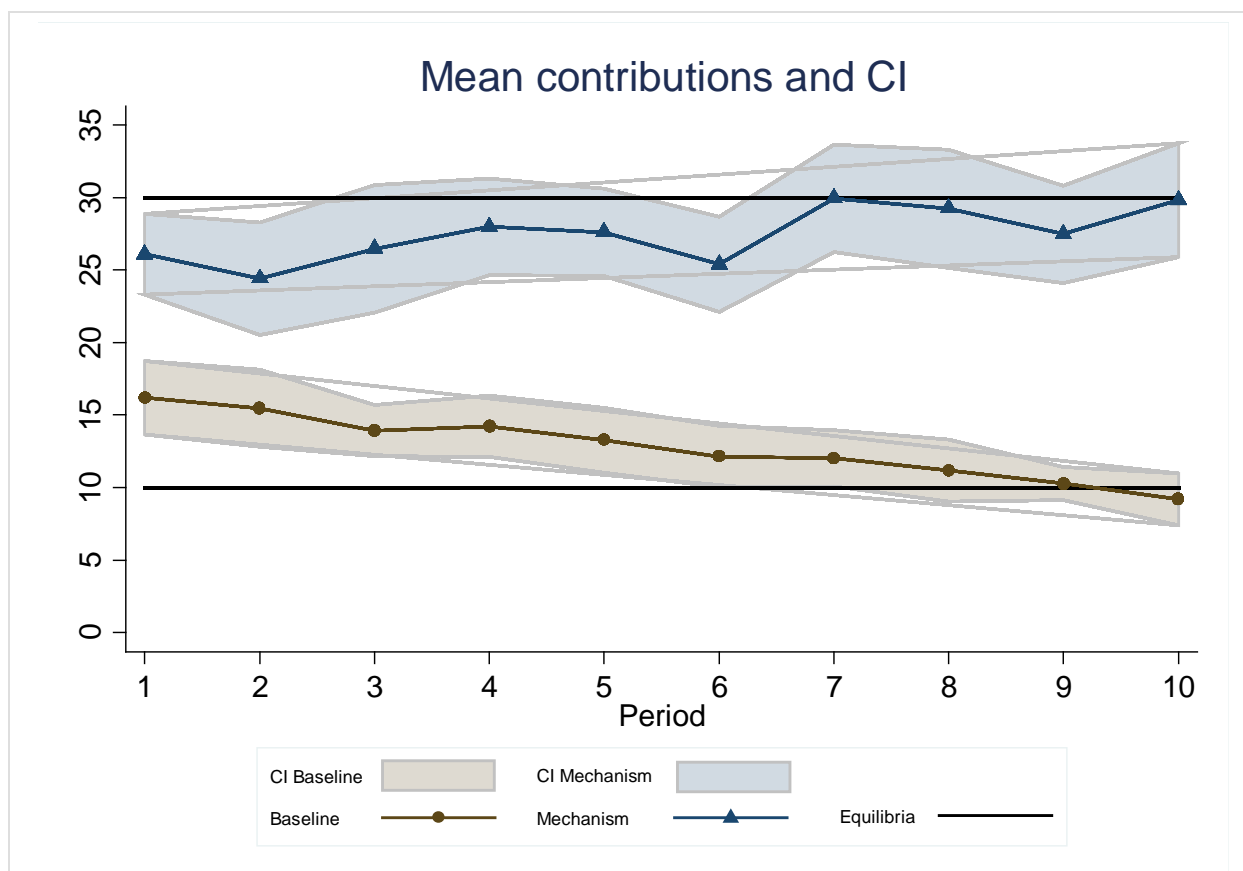

Note: Reported are the mean group contributions to the public good in the second stage for the periods 1-10. The equilibria are based on theoretical predictions. The Cls are calculated by bootstrapping.

\footnotetext{
${ }^{11}$ As the basis for the calculation of the Cls we use individual contributions, but we accounted for learning effects by drawing period 1-10 from the same group. For the random draws with replacement we use 1,000 bootstrap samples and the $95 \%$ interval.
} 
The mean contributions of each group are provided in Table 4 for the baseline treatment and in Table 5 for the mechanism treatment in the Appendix A1. The lowest (highest) mean group contribution over the ten rounds is 8.53 (18.20) in the baseline and 12.37 (44.35) in the mechanism treatment. The range of contributions is not that wide in Falkinger et al. (2000) with an exogenously given parameter.

Looking at the group dynamics of individual's contribution over the ten periods (Figure 5 and Figure 6, Appendix A2) in more detail, we see only in a few groups in the baseline treatment that the individual contributions vary, whereas most groups play the same strategy over the ten rounds with roughly equal contributions. In the mechanism treatment the individuals' contributions vary widely, but in more than half of the groups the individuals show stable behaviour in contributing roughly the same over the 10 periods. The individual level supports the previous results on group average: i) group contributions vary more widely in the mechanism treatment than in baseline, ii) first half contributions are higher and vary more widely than second half contributions in the baseline treatment whereas in mechanism the contrary is the case, iii) in baseline a tendency towards overcontribution and in mechanism towards under-contribution is observable like in Falkinger et al. (2000).

Result 1: The contributions in the mechanism treatment are significantly higher than in baseline. On average and on group level, under-contribution in the mechanism treatment is observable.

Nevertheless, the second stage equilibrium depends on the first stage's endogenously specified enforcement parameter. The mean group contribution to the enforcement mechanism is $7.84(5.23 \%$ of the endowment) and the resulting $\beta$ ranges from 0 to 0.98 (see Table 2). ${ }^{12}$ However, the most individuals contribute between zero and five in the first stage and only $0.72 \%$ of the contribution decisions are higher than 25 , which is the theoretical upper bound of first stage contribution (see). ${ }^{13}$ The variation of the contribution to the enforcement mechanism in the last period only ranges from 0 to 7 , which might be explained by learning effects. Almost $40 \%$ contributed nothing to the enforcement mechanism. This leads to the question how many groups result in a $\beta=0$ and if their contributions in the second stage are then in line with the baseline equilibria. Overall eleven times $\beta=0$ was realized by 5 different groups (with 4 group repeatedly realizing $\beta=0$ ). The $42.42 \%$ of the individuals confronted with a $\beta=0$ contributed 10 LD to the public good in the second stage, which is in line with the baseline equilibria. The theoretically optimal enforcement parameter with $\beta=2 / 3$ was reached 19 times in 10 different groups. 10.53\% of individuals played the equilibrium of 30 LD in the second stage when $\beta=2 / 3$ was realized.

\footnotetext{
${ }^{12}$ The high values result from some very high contributions, which might indicate that subjects did not understand how the mechanism works.

13 The upper bound of first stage contribution is based on the theoretical proposition that average contributions to the enforcement mechanism are never higher than half of the endowment by Buchholz et al. (2014), which is in our case 25.
} 
Figure 2: Individuals' contribution to enforcement mechanism in stage 1 periods 1-10

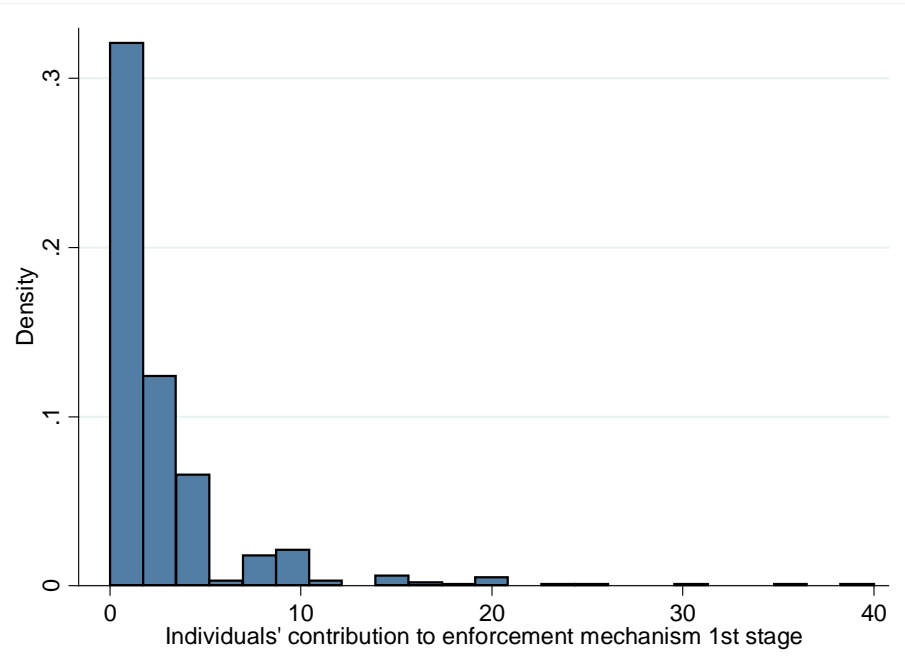

Note: Reported is the density of the individual's contribution to the enforcement mechanism over the period 1-10.

Furthermore, an overview on the individuals' contributions to the enforcement mechanism (Figure 7, Appendix A3) shows that in most groups low levels of first stage contributions are observable, which is in line with the theory. Nevertheless, in a small number of cases the group ends up with a zero enforcement mechanism. This is on the one hand due to the fact that for the implementation only one group member needs to contribute (Figure 3) and on the other hand that we ensured the understanding of the game by control questions.

Figure 3: Frequency of realized enforcement parameter periods 1-10

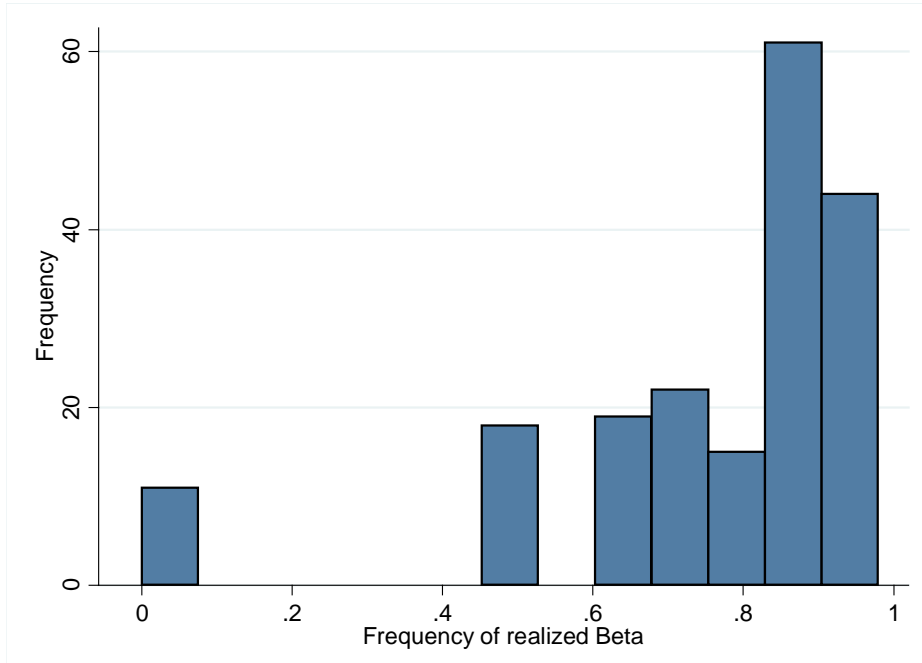

Note: Reported is the frequency of the realized enforcement parameter beta of all periods 1-10.

Result 2: Subjects are willing to establish norm-enforcement with their donations at the first stage.

The motivation for establishing the norm at the first stage could be strategical or intrinsical. A linear regression of the first stage contributions to the enforcement parameter shows neither significant effects of the socio-demographic nor of the behavioural variables (risk, trust, social-norm indicator) 
of the post-questionnaire. We run regressions for each period. In period 1 none of the explanatory variables was significant, contrary to punishment settings in which trust increases punishment (e.g. Kocher et al. 2012).

In the second stage contributions to the public good theoretically depend on the realized enforcement parameter. A higher enforcement parameter should lead to higher contributions to the public good (see red line in Figure 4). However, as the subjects' budgets are restricted in the first place and they can only spend the remaining money after the first round, the theoretical optima are not reachable at levels of $\beta \geq 0.8$ (see shaded area in Figure 4). Figure 4 shows that the group contributions increase with higher enforcement parameter, but are in most cases below the theoretical optima. The increase of group contributions according to the higher enforcement parameter is in line with the theoretical predictions and with empirical findings by Bracht et al. (2008). They varied the exogenously given parameter and found higher contributions the higher the given parameter was.

Figure 4: Group contributions by realized enforcement parameter

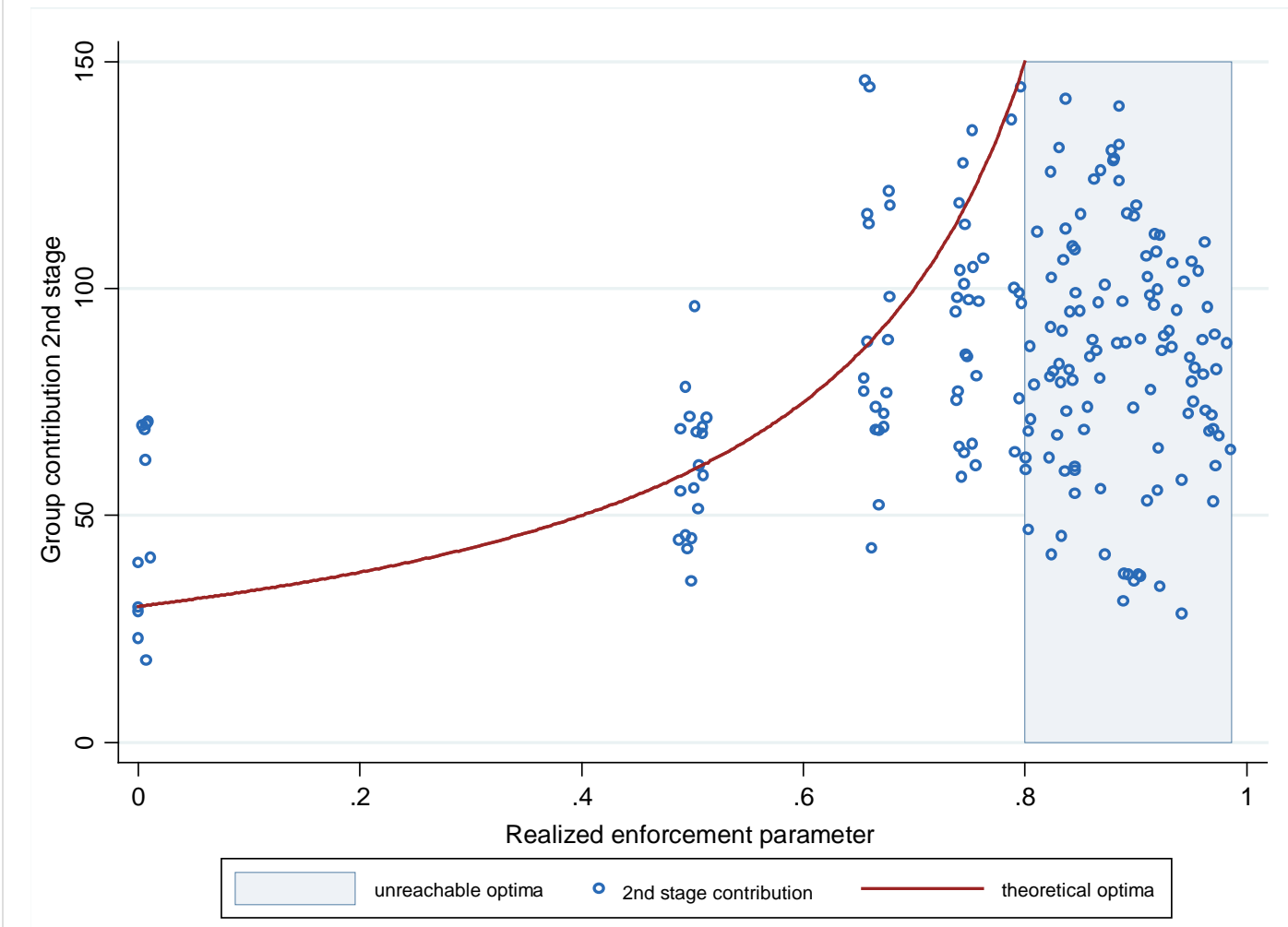

Note: Reported are the group contributions to the public good at the $2^{\text {nd }}$ stage by realized enforcement parameter. The red line shows the theoretically optimal group contribution based on the enforcement parameter. The shaded area marks the unreachable theoretical optima due to budget restrictions.

\section{Result 3: Mean group contributions tend to be higher the stronger the mechanism.}

Result 4: Group contributions tend to be lower than the calculated optimum based on realized enforcement mechanism.

Furthermore, we analyse the contributions on the group level with a linear regression (Table 3). Supporting previous result 1, the contributions in mechanism treatment are higher than in baseline. 
The influence of the enforcement parameter $\beta$ on the contributions at the group level is significant and depends on the niveau, supporting the previous results 4 and 5 .

Table 3: Linear regression of contribution on group level period 1-10

\begin{tabular}{lc}
\hline Variables & $\begin{array}{c}\text { Group contribution second } \\
\text { stage }\end{array}$ \\
\hline Baseline & $-13.9235^{* * *}$ \\
(treatment dummy) & $(0.5158)$ \\
Beta & $6.2105^{* * *}$ \\
& $(1.8080)$ \\
Beta^2 & $-6.3541^{* * *}$ \\
& $(1.6801)$ \\
Constant & $26.7294^{* * *}$ \\
& $(0.4891)$ \\
\hline No. of observations & 360 \\
$\mathrm{R}^{2}$ & 0.9356 \\
\hline Robust standard errors in parentheses. \\
Significance levels: $* * * \mathrm{p}>0.01, * * \mathrm{p}<0.05, \mathrm{p}^{*}<0.10$ \\
\hline
\end{tabular}

In the second stage the effects of the expectations on public good contributions of the other group members and the realized enforcement parameter is not distinguishable. The expectations range from 0 to 50 with a mean of 23.8. It is not clear if the subjects base their decisions to contribute to the public good on their expectations or the realized enforcement parameter they are facing. Furthermore, individuals might base their expectations on the realized enforcement parameter (corr $=0.3353$ ). Nevertheless, a Pearson correlation of 0.6072 supports a positive relation of expectation and subject's own contribution. We can observe that $15.44 \%$ contributed the same amount as they expect as the other group members' average. $62.11 \%$ of the individuals (in the different rounds 1-10) contributed more than they expect as average contribution from the other two group members. Out of these individuals $42.97 \%$ (in the different rounds 1-10) invest in the enforcement mechanism in the first stage.

Result 5: Expectations on the contributions of the other group members and own contributions to the public good at the second stage are positively correlated.

\section{Discussion and Conclusion}

In this paper we focus on the enforcement of social norms induced by subjects who fund the enforcement mechanism themselves. We apply the theory by Buchholz et al. (2014) - an endogenous enforcement mechanism in a two-stage public good game - to a laboratory experiment. The design was also based on previous related laboratory experiments on different matching mechanisms by Falkinger et al. (2000) and Bracht et al. (2008). In our case, the individuals themselves introduced the enforcement mechanism by their own voluntary contributions, contrary to related experiments with an exogenously given parameter (see Falkinger et al. 2000, Bracht et al. 2008).

As in line with experimental results, the contribution in such games with a mechanism is higher than without. Even if Pareto efficient outcomes are not reached, the public good provision is higher in the mechanism case. In our sample only a few groups ended with a zero enforcement mechanism because only one contributing individual is needed to implement an enforcement mechanism. This result indicates that subjects are apparently willing to contribute funds for implementing an enforcement mechanism. This willingness to voluntarily contribute to the enforcement mechanism is 
not necessarily due to altruistic motives, but might also be in line with pure self-interest. There is a strategic component involved: While direct voluntary contributions of one dollar to the intrinsic public good on stage two of the game brings about additional public good consumption only of a one-dollar worth, the same dollar spent on the first stage may induce a multiplier effect: the donated dollar might bring about a large number of individuals to contribute a value to the public good which is much higher than the initially spent dollar. And although the agent donating on the first stage also is induced to raise his contribution on the second stage, the multiplier effect may compensate for the higher burden this individual will face, i.e. he can gain from the rewarding scheme. The experiment also shows that the expected average contributions of the group members are correlated with the own public good provision. Further research would be needed to separate effects of expectations and the realized enforcement parameter on the public good provision. Moreover, further research would be needed to analyse the endogenous norm-enforcement mechanism in more detail in the laboratory as well as in the field, e.g. with different group sizes, heterogeneous players, distinction between finance and target groups, and alternative underlying social norms.

Nevertheless, our results might be instructive for non-governmental organizations which could exploit the norm-setting/enforcing mechanism in pursuing their objectives of private public good provision. Even though our reward scheme was monetized, the results indicate that people are willing to pay for such norm-enforcement. Furthermore, the orientation of the subjects towards the expected contributions of the other group members reveals that social norms strongly influence subjects in their decision making. Both the orientation on social norms and the willingness to contribute for the implementation of an enforcement mechanism for such norms can also provide implications for law makers, as legal enforcement is likewise based on social norms. 


\section{References}

Allcott, H. (2011), Social norms and energy conservation, Journal of Public Economics 95(9-10), 10821095.

Andreoni, J. (1988), Why free ride? Strategies and learning in public goods experiments, Journal of Public Economics 37(3), 291-304.

Andreoni, J. (1993), An experimental test of the public-goods crowding-out hypothesis, American Economic Review 83(5), 1317-1327.

Andreoni, J. and T. Bergstrom (1996), Do Government subsidies increase the private supply of public goods?, Public Choice 88, 295-308.

Andreoni, J. and H.R. Varian (1999), Pre-play contracting in the prisoners' dilemma, Proceedings of the National Academy of Sciences of the United States of America 96, 10933-10938.

Axelrod, R. (1986), An evolutionary approach to norms, The American Political Science Review 80(4), 1095-1111.

Azar, O.H. (2004), What sustains social norms and how they evolve? The case of tipping, Journal of Economic Behavior and Organization 54, 49-64.

Baker, R.J., J.M. Walker and A.W. Williams (2009), Matching contributions and the voluntary provision of a pure public good: Experimental evidence, Journal of Economic Behavior and Organization 70, 122-134.

Bracht, J., C. Figuières and M. Ratto (2008), Relative performance of two simple incentive mechanisms in a public goods experiment, Journal of Public Economics 92, 54-90.

Buchholz, W., R. Cornes and D. Rübbelke (2011), Interior matching equilibria in a public good economy: an aggregative game approach, Journal of Public Economics 95(7-8), 639-645.

Buchholz, W., J. Falkinger and D. Rübbelke (2014), Non-governmental public norm enforcement in large societies as a two-stage game of voluntary public good provision, Journal of Public Economic Theory, forthcoming.

Coleman, J. (1990), Foundations of social theory, Belknap Press/Harvard University Press.

Cornes, R. and T. Sandler (1985), The simple analytics of pure public good provision, Economica 52(205), 103-116.

Ellickson, R.C. (2001), The evolution of social norms: a perspective from the legal academy, in: Hechter, M. and K-D. Opp (Eds.), Social norms, Russel Sage Foundation, New York, 35-75.

Ertan, A., T. Page and L. Putterman (2009), Who to punish? Individual decisions and majority rule in mitigating the free rider problem, European Economic Review 53, 495-511.

Falkinger, J. (1996), Efficient private provision of public goods by rewarding deviations from average, Journal of Public Economics 62, 413-422. 
Falkinger, J., E. Fehr, S. Gächter and R. Winter-Ebmer (2000), A simple mechanism for the efficient provision of public goods: experimental evidence, American Economic Review 90(1), 247-264.

Fehr, E. and U. Fischbacher (2004), Social norms and human cooperation, TRENDS in cognitive Sciences 8(4), 185-190.

Fehr, E. and U. Fischbacher (2004), Third-party punishment and social norms, Evolution and Human Behavior 25, 63-87.

Fehr, E., U. Fischbacher and S. Gächter (2002), Strong reciprocity, human cooperation, and the enforcement of social norms, Human Nature 13(1), 1-25.

Fehr, E. and S. Gächter (2000), Cooperation and punishment in public goods experiments, The American Economic Review 90(4), 980-994.

Fischbacher, U. (2007), z-Tree: Zurich toolbox for ready-made economic experiments, Experimental Economics 10(2), 171-178.

Greiner, B. (2004), An online recruitment system for economic experiments, in: Forschung und wissenschaftliches Rechnen, Kremer, K., Macho, V. (Eds.), GWDG Bericht 63, Gesellschaft für Wissenschaftliche Datenverarbeitung Göttingen, 79-93.

Guttman, J.M. (1978), Understanding collective action: matching behavior, The American Economic Review 68(2), Papers and Proceedings of the Ninetieth Annual Meeting of the American Economic Association, 251-255.

Guttman, J.M. (1986), Matching behavior and collective action: some experimental evidence, Journal of Economic Behavior and Organization 7, 171-198.

Guttman, J.M. (2013), On the evolution of conditional cooperation, European Journal of Political Economy 30, 15-34.

Hechter M. and K-D. Opp (2001), Introduction, in: Hechter, M. and K-D. Opp (Eds.), Social Norms, Russel Sage Foundation, New York, xi-xx.

Horne, C. (2001), Sociological perspectives on the emergence of norms, in: Hechter, M. and K-D. Opp (Eds.), Social Norms, Russel Sage Foundation, New York, 3-34.

Keser, C. (1996), Voluntary contributions to a public good when partial contribution is a dominant strategy, Economics Letters 50, 359-366.

Kocher, M., P. Martinsson and M. Visser (2012), Social background, cooperative behaviour, and norm enforcement, Journal of Economic Behavior and Organization 81, 341-354.

Kosfeld, M., A. Okada and A. Riedl (2009), Institution formation in public goods games, The American Economic Review 99(4), 1335-1355.

Laury, S.K. and C.A. Holt (2008), Voluntary provision of public goods: experimental results with interior Nash equilibria, Handbook of experimental economics results, Volume 1, Chapter 84, 792-801. 
Ledyard, J.O. (1995), Public goods: a survey of experimental research, in: J. Kagel and A.E. Roth (Eds.), Handbook of experimental economics, Princeton University Press, New York.

Lindbeck, A., S. Nyberg and J.W. Weibull (1999), Social norms and economic incentives in the welfare State, Quarterly Journal of Economics CXIV(1), 1-35.

Löschel, A. and D. Rübbelke (2014), On the voluntary provision of international public goods, Economica 81(322), 195-204.

Mengel, F. (2008), Matching structure and the cultural transmission of social norms, Journal of Economic Behavior and Organization 67, 608-623.

Ostrom, E. (2000), Collective action and the evolution of social norms, The Journal of Economic Perspectives 14(3), 137-158.

Rege, M. (2008), Why do people car about social status?, Journal of Economic Behavior and Organization 66, 233-242.

Schultz W., J.M. Nolan, R.B. Cialdini, N.J. Goldstein and V. Griskevicius (2007), The constructive, destructive, and reconstructive power of social norms, Psychological Science 18(5), 429-434.

Sefton M. and R. Steinberg (1996), Reward structures in public good experiments, Journal of Public Economics 61(2), 263-288.

Sethi, R. and E. Somanathan (1996), The evolution of social norms in common property resource use, The American Economic Review 86(4), 766-788.

Voss, T. (2001), Game-theoretical perspectives on the emergence of social norms, in: Hechter, M. and K-D. Opp (Eds.), Social norms, Russel Sage Foundation, New York, 105-138. 


\section{Appendix}

\section{A1: Summary statistics for each group}

Table 4: Summary statistics of the baseline treatment by groups

\begin{tabular}{|c|c|c|c|c|}
\hline Group & $\begin{array}{c}\text { Mean* } \\
\text { periods 1-10 }\end{array}$ & $\begin{array}{c}\text { Mean } \\
\text { periods 1-5 }\end{array}$ & $\begin{array}{c}\text { Mean } \\
\text { periods 6-10 }\end{array}$ & $\begin{array}{c}\text { Median } \\
\text { periods } 1-10\end{array}$ \\
\hline 1 & 10.27 & 12.00 & 8.53 & 10.00 \\
\hline 2 & 9.73 & 11.80 & 7.67 & 10.00 \\
\hline 3 & 12.20 & 14.07 & 10.33 & 10.83 \\
\hline 4 & 10.30 & 10.33 & 10.27 & 10.17 \\
\hline 5 & 18.20 & 20.73 & 15.67 & 19.17 \\
\hline 6 & 15.00 & 16.33 & 13.67 & 15.00 \\
\hline 7 & 16.07 & 19.47 & 12.67 & 15.17 \\
\hline 8 & 9.90 & 10.13 & 9.67 & 9.50 \\
\hline 9 & 8.53 & 6.13 & 10.93 & 8.00 \\
\hline 10 & 11.60 & 13.86 & 9.33 & 10.00 \\
\hline 11 & 10.47 & 11.47 & 9.47 & 10.00 \\
\hline 12 & 17.93 & 24.87 & 11.00 & 18.00 \\
\hline 13 & 16.43 & 17.20 & 15.67 & 18.00 \\
\hline 14 & 10.23 & 11.67 & 8.80 & 10.00 \\
\hline 15 & 14.43 & 17.13 & 11.73 & 15.00 \\
\hline 16 & 9.77 & 12.40 & 7.13 & 8.33 \\
\hline 17 & 16.63 & 19.20 & 14.07 & 16.00 \\
\hline Total for all groups & 12.81 & 14.63 & 10.98 & 12.54 \\
\hline
\end{tabular}

*Only payoff relevant periods are included, not the two training periods at the beginning.

Table 5: Summary statistics of the mechanism treatment by groups

\begin{tabular}{|c|c|c|c|c|}
\hline Group & $\begin{array}{c}\text { Mean* } \\
\text { periods 1-10 }\end{array}$ & $\begin{array}{c}\text { Mean } \\
\text { periods 1-5 }\end{array}$ & $\begin{array}{c}\text { Mean } \\
\text { periods 6-10 }\end{array}$ & $\begin{array}{c}\text { Median } \\
\text { periods } 1-10\end{array}$ \\
\hline 18 & 29.17 & 31.33 & 27.00 & 30.83 \\
\hline 19 & 38.23 & 38.00 & 38.47 & 38.50 \\
\hline 20 & 34.80 & 28.80 & 40.80 & 34.67 \\
\hline 21 & 21.03 & 22.67 & 19.80 & 22.33 \\
\hline 22 & 25.37 & 26.20 & 24.53 & 25.50 \\
\hline 23 & 27.80 & 27.20 & 28.40 & 26.67 \\
\hline 24 & 26.03 & 26.33 & 25.73 & 25.67 \\
\hline 25 & 25.67 & 21.40 & 29.13 & 24.83 \\
\hline 26 & 19.77 & 18.80 & 20.73 & 20.33 \\
\hline 27 & 26.80 & 26.87 & 26.73 & 26.67 \\
\hline 28 & 25.30 & 24.13 & 26.46 & 25.50 \\
\hline 29 & 12.37 & 11.07 & 13.67 & 11.83 \\
\hline 30 & 35.40 & 31.93 & 38.87 & 35.33 \\
\hline 31 & 29.37 & 26.60 & 32.13 & 30.83 \\
\hline 32 & 44.35 & 41.00 & 47.51 & 45.00 \\
\hline 33 & 33.73 & 39.13 & 28.33 & 35.33 \\
\hline 34 & 19.18 & 22.10 & 16.27 & 20.00 \\
\hline 35 & 20.07 & 18.00 & 22.13 & 21.33 \\
\hline 36 & 27.63 & 22.73 & 32.53 & 25.67 \\
\hline Total for all groups & 27.47 & 26.75 & 28.15 & 27.84 \\
\hline
\end{tabular}

*Only payoff relevant periods are included, not the two training periods at the beginning. 


\section{A2: Individual's $2^{\text {nd }}$ stage contributions over ten rounds}

Figure 5: Individuals' $2^{\text {nd }}$ stage contributions over period 1-10 in the baseline treatment

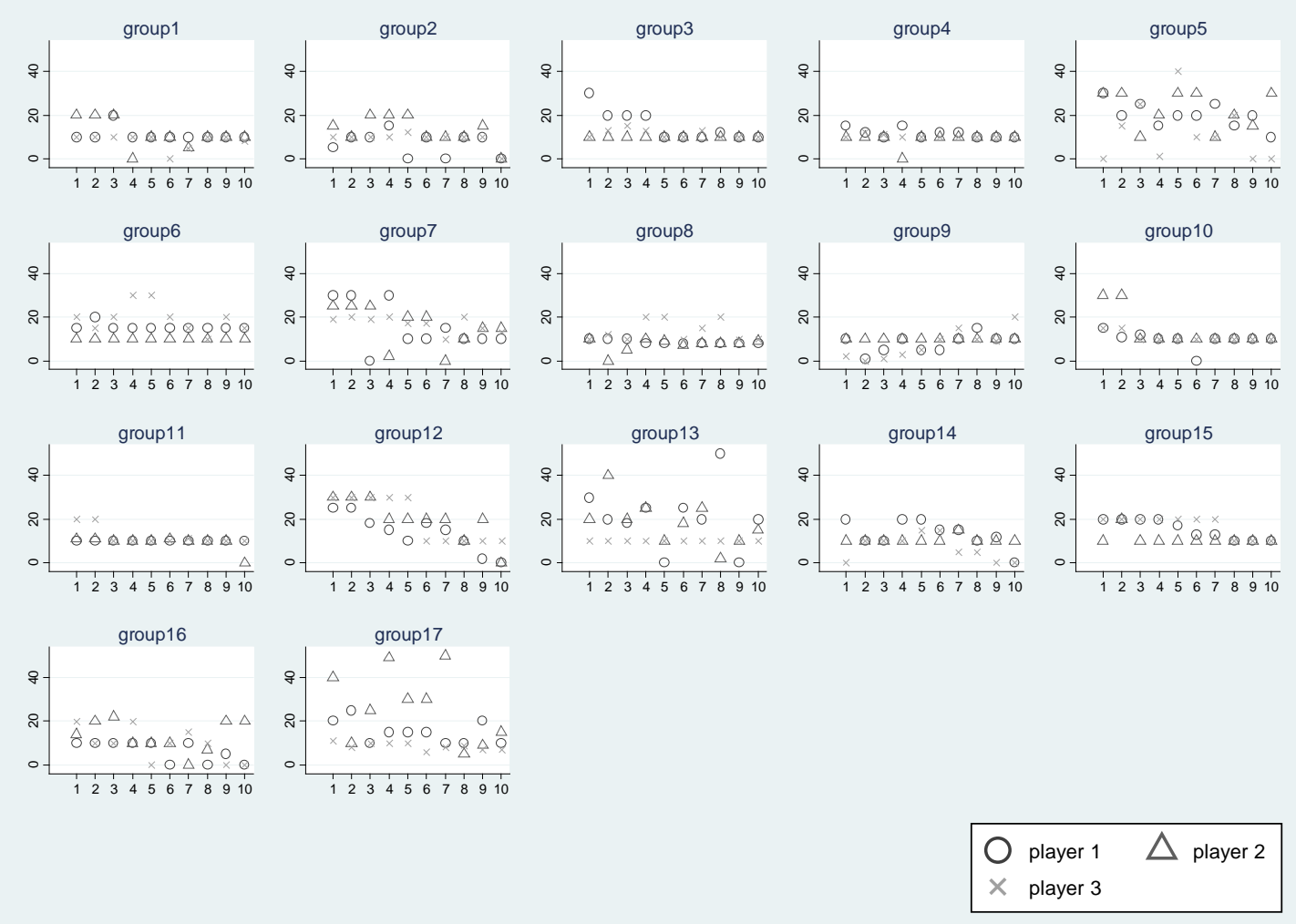

Figure 6: Individuals' $2^{\text {nd }}$ stage contributions over period 1-10 in the mechanism treatment
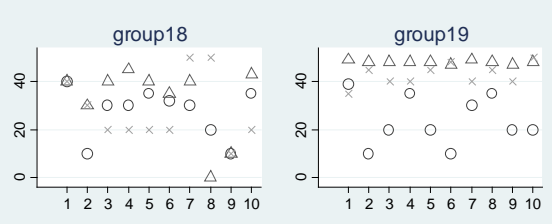

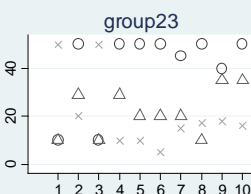
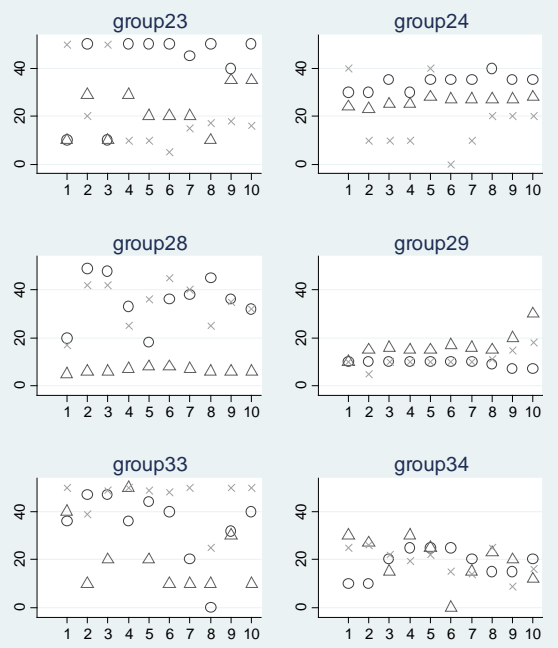

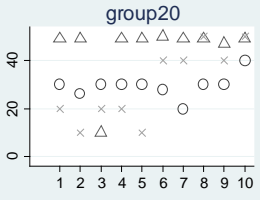

group25

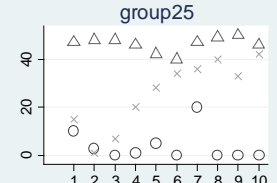

group30

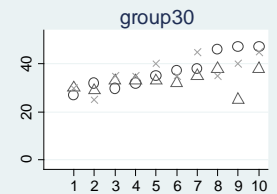

group35

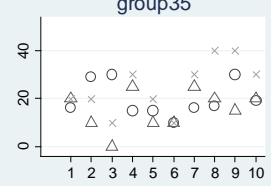

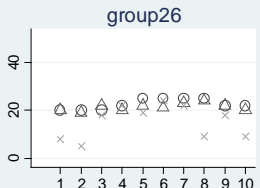
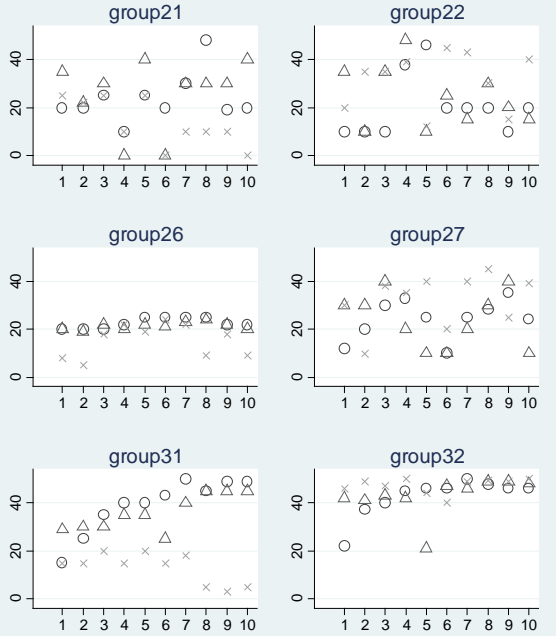

group36

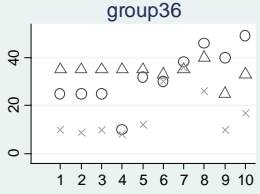

player 1 player 3 


\section{A3: Individual's $1^{\text {st }}$ stage contributions over ten rounds}

\section{Figure 7: Individuals' contributions over period 1-10 to the enforcement mechanism}
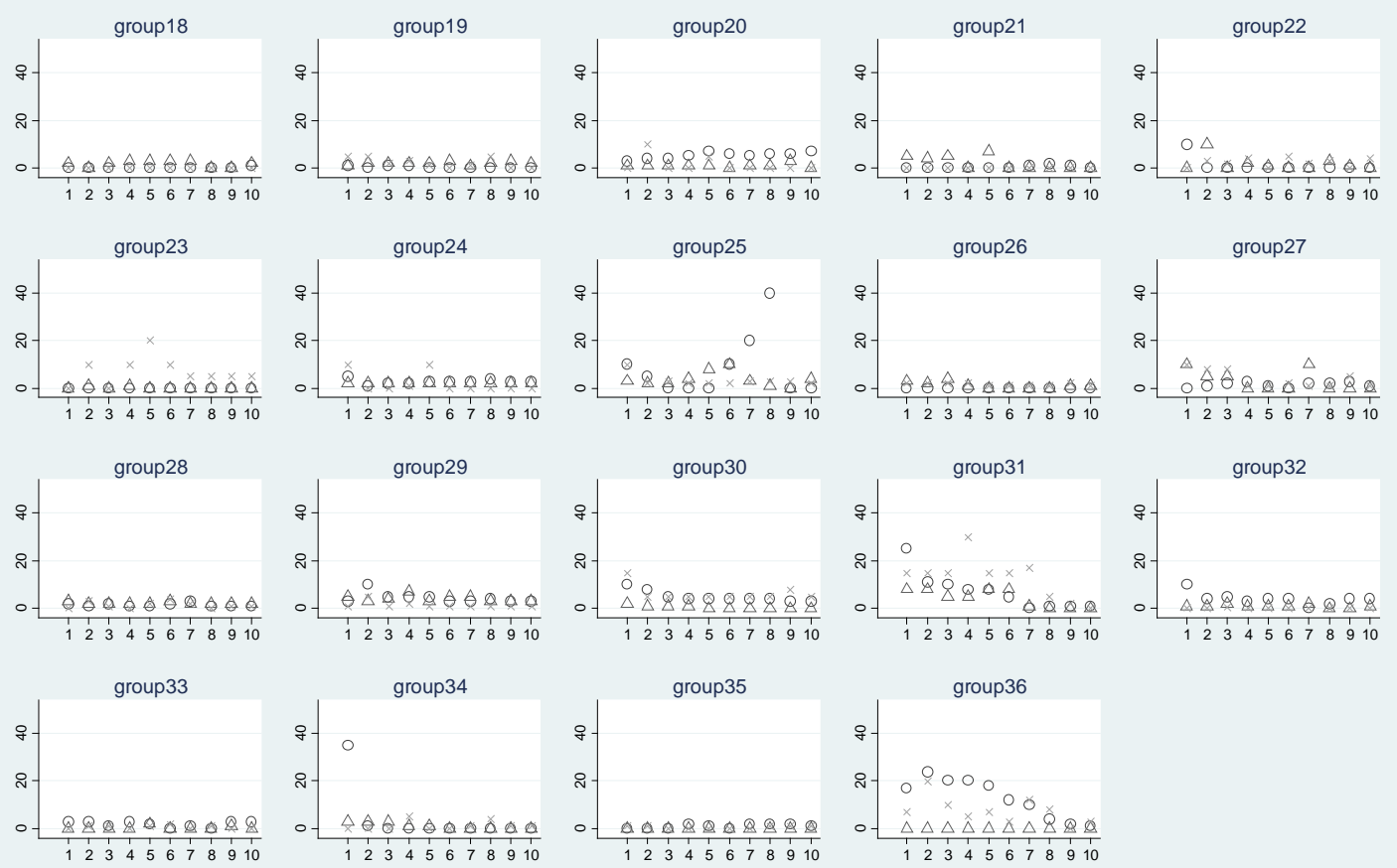

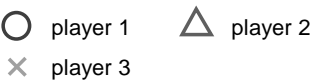




\section{A4: Instructions mechanism treatment (translated from German) ${ }^{14}$}

Welcome to our Experiment!

Thank you for participating. Please keep your mobile phones turned off during the whole experiment. Please do not talk to other participants. Now, please carefully read the following rules of the game.

If you have any questions, please raise your hand. A staff member will gladly answer your question.

Regardless of the course of the game you will receive 4 euros for your participation. During the experiment you can earn more money. Your additional earnings depend on the course of the game, i.e. on your own decisions and those of the other participants in the game. In the experiment, the only currency we calculate with is LaborDollars (LD). At the end of the experiment, the LD are converted into euro. The conversion rate is:

\section{$1 \mathrm{LD}=0.08$ EUR}

You make your decisions anonymously in the experiment. Only the staff will know your identity and your information will be kept confidential.

\section{Rules}

Three players take part in the game, i.e. apart from you, there are two other players. The composition of your group remains the same during the whole experiment. Each player has the same decision problem. You make your decisions anonymously. To ensure this, you will be given a player number for the duration of the game.

The three of you play ten independent games in a row. At the beginning of each game, you will receive an initial endowment of $\mathbf{5 0}$ LD. In each game, you make a decision for the use of your initial endowment. After the experiment, one of the ten games will be randomly selected for the payoff by the computer. Your income from the selected game will be converted from LD into euro. When you leave the lab, you will be paid this amount together with the lump sum of 4 euros. In the beginning, there will be two trial games, which are not relevant for disbursement.

One game consists of two independent stages, respectively. The overall result depends on your decisions and those of the other participants in your group. Your task in the game (just like that of the other players in your group) is to make decisions, in two stages, on contributions to an institution, a joint project, and a private account.

In the first stage you can invest in an institution. Through this institution, above-average contributions to a joint project will be rewarded and those below-average will be penalised.

In the second stage, you decide how many LD of the remaining amount from your initial endowment (remaining endowment) you want to contribute to a joint project and your private account.

\section{Decision Situation}

First stage

In the beginning of each game, every player receives 50 LD. In the first stage, you and the other players are asked to invest any amount in an institution. Depending on this investment, above-average contributions to a joint project will be rewarded and below-average contributions will be penalised in the second stage. Each LD that you do not invest in the first stage can be used as the remaining endowment for the second stage.

\section{Remaining endowment $\mathbf{=} \mathbf{5 0}-$ (your investment in the institution)}

The amount of investments of all group members determines the so called multiplication factor, according to Table A, which defines the intensity of the reward or the penalty. The first column in Table A indicates the sum of all investments in the institution. The second column indicates the corresponding multiplication factor. In the third column, the variation of the multiplication factor if one more unit is invested in the institution is listed. If, for example, 0 LD were invested, the multiplication factor in the second stage is 0 . If, for example, a total of 3 LD were invested in the institution, the multiplication factor in the second stage is 0.75 .

After entering your investment in the institution, you have to click on the "next" button. Afterwards, you cannot change your decision in the current game anymore. When all the group members made their investment decisions, the results of this stage will be displayed on the screen. In the upper half, you will find the results of all the previous games, and in the lower half, you will find the results of the current game.

Second stage

In the second stage of the game, you and the other players are asked to make a decision on the contribution to a joint project. For this purpose, you can use the remaining endowment from stage 1 and invest any amount in the joint project.

The remaining amount of LD for your private account depends on the investments of all group members in the institution in the first stage and their contributions to the joint project in the second stage. In the following, direct and indirect contributions to the private account will be distinguished. Thus, they present the total contribution to your private account.

Apart from entering your contribution to the joint project, you have to enter your expectation regarding the average contribution of all group members to the joint project. This expectation does not influence your payment and is not communicated to anyone. After entering your contribution to the joint project and the expected group average, you have to click the "Next" button. Afterwards, you cannot change your decision in the current game anymore

\footnotetext{
${ }^{14}$ Note: In the baseline treatment there is no first stage.
} 
After all the group members made their decisions for the contribution to the joint project and entered their expectations, the results of this game will be displayed on the screen. In the upper half you, will find the results of all the previous games, and in the lower half, you will find the results of the current game.

\section{Calculation of Your Income} Income from the joint project

The income from the joint project is composed as follows for every member of the group:

\section{Income from the joint project $=$ Sum of all contributions to the joint project}

Each group member receives the same income from the joint project. If, for example, the total sum of all contributions is 10 LD, each group member receives $10 \mathrm{LD}$ as the income from the joint project.

For each LD that you contribute to the joint project, your income increases by one LD and so does the income of the other group members. Through your contribution to the joint project, the other group members also gain money, but you also gain through the contributions of the other group members to the joint project.

Income from your private account

a) Direct contribution to the private account

The part of the remaining endowment that you do not contribute to the joint project is the direct contribution to your private account.

\section{Direct contribution to your private account $=$ Remaining endowment - your contribution to the joint project}

b) Indirect contribution to the private account

The indirect contribution to your private account depends on the investments of all group members in the institution in the first stage and their contributions to the joint project in the second stage. The indirect contribution is calculated as:

\section{Indirect contribution to your private account}

$=($ Your contribution to the joint project - average contribution of the two other group members to the joint project) $\times$ (multiplication factor according to Table A)

If, for example, 3 LD were invested in the institution in the first stage, this yields a multiplication factor of 0.75 according to Table A. If, for example, you contribute 10 LD to the joint project in the second stage and the other two group members have an average contribution of $20 \mathrm{LD}$, the indirect contribution to your private account is: $(10-20) \times$ (multiplication factor according to Table A). The indirect contribution is negative then (-7.5 LD). Conversely, if you contribute 20 LD to the joint project and the other two group members contribute 10 LD on average, the indirect contribution to your private account is positive. If the multiplication factor is the same (0.75), the indirect contribution is +7.5 LD.

In general, the indirect contribution to your private account is positive if your contribution to the joint project is higher than the average contribution of the other group members to the joint project. The indirect contribution to your private account is negative if your contribution to the joint project is less than the average contribution of the other group members to the joint project.

The multiplication factor determines how positive or negative the indirect contribution to the private account is. Consequently, the more was invested altogether in the institution by all group members in the first stage, the heavier a deviation from the average contribution of the other group members is rewarded or penalised. The lower the complete investment in the institution in the first stage, the more leniently a deviation from the average contribution in the joint project of the other group members is rewarded or penalised. Each LD of your contribution that exceeds the average contribution to the joint project of the other group members increases the indirect contribution to your private account by the multiplication factor determined in the first stage. In contrast, each LD of your contribution which is below the average contribution to the joint project of the other group members reduces the indirect contribution to your private account by the multiplication factor determined in the first stage.

Total contribution to the private account

The total contribution to the private account consists of the direct and the indirect contributions.

\section{Total contribution to the private account}

\section{$=$ Direct contribution to the private account + indirect contribution to the private account}

The total contribution to the private account therefore depends on your contribution to the joint project, their relation to the contributions to the joint project of the other group members, as well as the investments in the first stage.

After the instructions you will find a schematic diagram of the correlations. In the upper half, you will find the diagram that shows the case in which you invest an additional LD in the joint project. In the lower half, you will find the diagram for the case in which an additional LD is invested in the joint project by the two other group members. Each LD that you contribute to the joint project, increases your income from the joint project by one unit and reduces the direct contribution to the private account by one unit. However, your contribution to the joint project increases in relation to that of the other group members, whereby the indirect contribution to your private account increases by the multiplication factor. Each additional LD to the joint project does not reduce the total contribution to your private account by one unit, but by $(1-$ multiplication factor). 
If each of the two other group members increases his/her contribution to the joint project by one LD, your income from the joint project rises by 2 LD. In contrast, your indirect contribution to your private account by the multiplication factor since the average contribution to the joint project of the other group members increases by one unit compared to your contribution.

The income from your private account is calculated for all group members using the same formula:

$$
\text { Income from private account }=5 \times(\text { Contribution to own account })-0.05 \times(\text { contribution to own account })^{2}
$$

The attached table B shows your income from the private account for every amount of your contribution to the private account. Unlike in the joint project, in which all group members profit from your contribution, only you can earn money from a contribution to your private account.

If you, for example, contribute 0 LD to your private account, your income from the private account is 0 LD. If you contribute 50 LD to your private account, your income from the private account is 125 LD (see table). The income from the private account solely depends on your contribution to your private account.

In the attached table B, you will find your potential total contributions to the private account in LD in the first column. In the second column, the respective income from the private account is listed in LD. The third column shows the change in income if the total contribution to your private account increases by one unit. The fourth column indicates the change in income if one more unit is invested in the joint project. You see that your income increases by exactly one unit if you or another group member invests an additional LD in the joint project. In contrast, the change in income from your contributions to your private account does not remain constant. The change in income is less the higher the total contribution to your private account already is. If your total contribution to the private account is already high, a further contribution to the private account generates a relatively low additional income from the private account. If, however, your total contribution to your private account is low, a further contribution to the private account generates a relatively high additional income.

\section{Total income}

The total income is calculated from the income from the joint project and the income from the private account.

\section{Total income $=$ Income from the joint project + income from the private account}

After the experiment, one of the ten games is selected randomly by the computer for payoff. Therefore, in each stage, you should act as if it was relevant to disbursement. Your income from the selected game will be converted from LD into euro. When you leave the lab, you will be paid this amount together with the lump sum of 4 euros.

In the beginning, there will be two trial games, which are not relevant for disbursement. 
Schematic Diagram

1 additional LD to the joint project from you

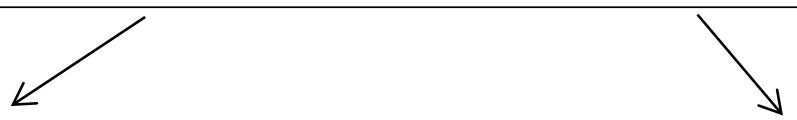

Increases the contribution to the joint project by 1 unit and hence your income from the joint project by 1 unit
Reduces the direct

contribution to the private

account

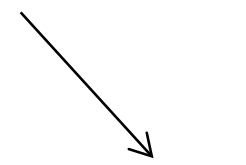

Reduces the total contribution to your private account by (1 multiplication factor) units
Increases the indirect contribution to the private account by the multiplication factor (determined by investments in the first stage)

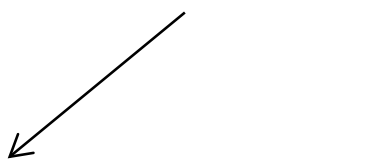


Table A: Multiplication factor

\begin{tabular}{|c|c|c|}
\hline $\begin{array}{l}\text { Sum of contributions of } \\
\text { all group members to } \\
\text { the institution in LD }\end{array}$ & $\begin{array}{l}\text { Multiplication } \\
\text { factor }\end{array}$ & $\begin{array}{l}\text { Change of the } \\
\text { multiplication } \\
\text { factor if one more } \\
\text { unit is contributed } \\
\text { to the institution }\end{array}$ \\
\hline 0 & 0.00000 & 0.50000 \\
\hline 1 & 0.50000 & 0.16667 \\
\hline 2 & 0.66667 & 0.08333 \\
\hline 3 & 0.75000 & 0.05000 \\
\hline 4 & 0.80000 & 0.03333 \\
\hline 5 & 0.83333 & 0.02381 \\
\hline 6 & 0.85714 & 0.01786 \\
\hline 7 & 0.87500 & 0.01389 \\
\hline 8 & 0.88889 & 0.01111 \\
\hline 9 & 0.90000 & 0.00909 \\
\hline 10 & 0.90909 & 0.00758 \\
\hline 11 & 0.91667 & 0.00641 \\
\hline 12 & 0.92308 & 0.00549 \\
\hline 13 & 0.92857 & 0.00476 \\
\hline 14 & 0.93333 & 0.00417 \\
\hline 15 & 0.93750 & 0.00368 \\
\hline 16 & 0.94118 & 0.00327 \\
\hline 17 & 0.94444 & 0.00292 \\
\hline 18 & 0.94737 & 0.00263 \\
\hline 19 & 0.95000 & 0.00238 \\
\hline 20 & 0.95238 & 0.00216 \\
\hline 21 & 0.95455 & 0.00198 \\
\hline 22 & 0.95652 & 0.00181 \\
\hline 23 & 0.95833 & 0.00167 \\
\hline 24 & 0.96000 & 0.00154 \\
\hline 25 & 0.96154 & 0.00142 \\
\hline
\end{tabular}

\begin{tabular}{|c|c|c|}
\hline $\begin{array}{l}\text { Sum of } \\
\text { contributions of all } \\
\text { group members to } \\
\text { the institution in LD }\end{array}$ & $\begin{array}{l}\text { Multiplication } \\
\text { factor }\end{array}$ & $\begin{array}{l}\text { Change of the } \\
\text { multiplication factor } \\
\text { if one more unit is } \\
\text { contributed to the } \\
\text { institution }\end{array}$ \\
\hline 71 & 0.98611 & 0.00019 \\
\hline 72 & 0.98630 & 0.00019 \\
\hline 73 & 0.98649 & 0.00018 \\
\hline 74 & 0.98667 & 0.00018 \\
\hline 75 & 0.98684 & 0.00017 \\
\hline 76 & 0.98701 & 0.00017 \\
\hline 77 & 0.98718 & 0.00016 \\
\hline 78 & 0.98734 & 0.00016 \\
\hline 79 & 0.98750 & 0.00015 \\
\hline 80 & 0.98765 & 0.00015 \\
\hline 81 & 0.98780 & 0.00015 \\
\hline 82 & 0.98795 & 0.00014 \\
\hline 83 & 0.98810 & 0.00014 \\
\hline 84 & 0.98824 & 0.00014 \\
\hline 85 & 0.98837 & 0.00013 \\
\hline 86 & 0.98851 & 0.00013 \\
\hline 87 & 0.98864 & 0.00013 \\
\hline 88 & 0.98876 & 0.00012 \\
\hline 89 & 0.98889 & 0.00012 \\
\hline 90 & 0.98901 & 0.00012 \\
\hline 91 & 0.98913 & 0.00012 \\
\hline 92 & 0.98925 & 0.00011 \\
\hline 93 & 0.98936 & 0.00011 \\
\hline 94 & 0.98947 & 0.00011 \\
\hline 95 & 0.98958 & 0.00011 \\
\hline 96 & 0.98969 & 0.00011 \\
\hline
\end{tabular}




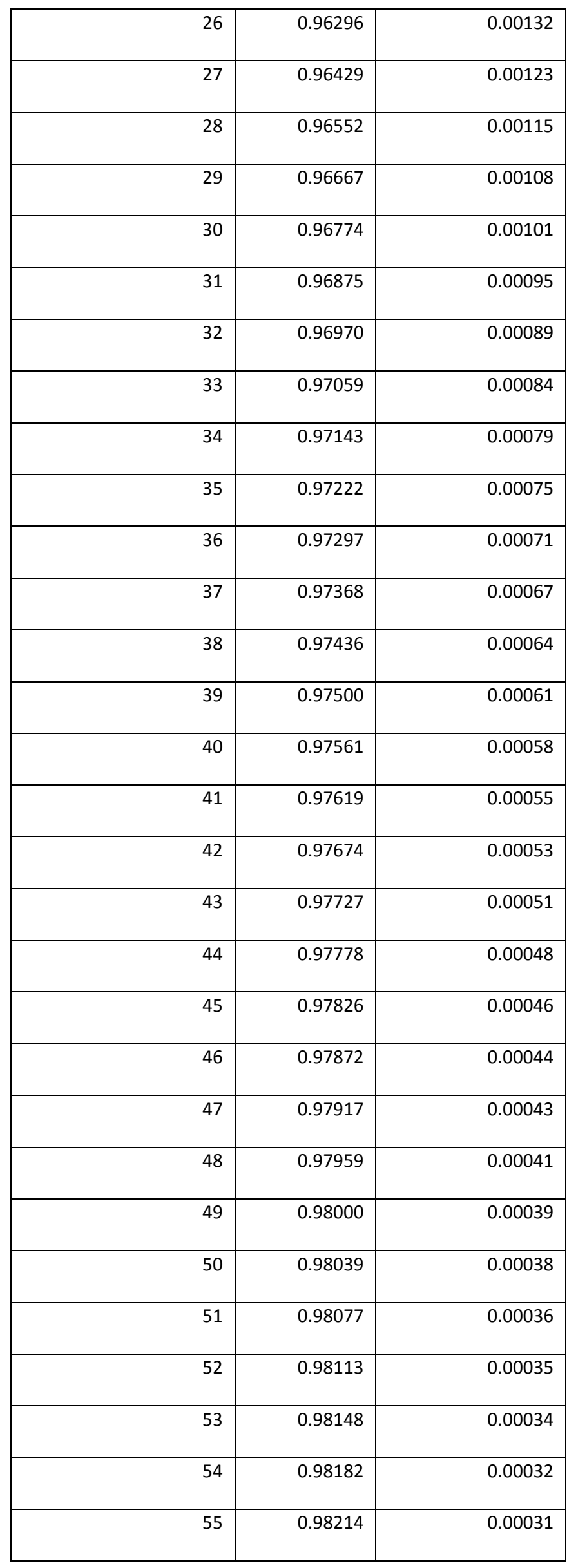

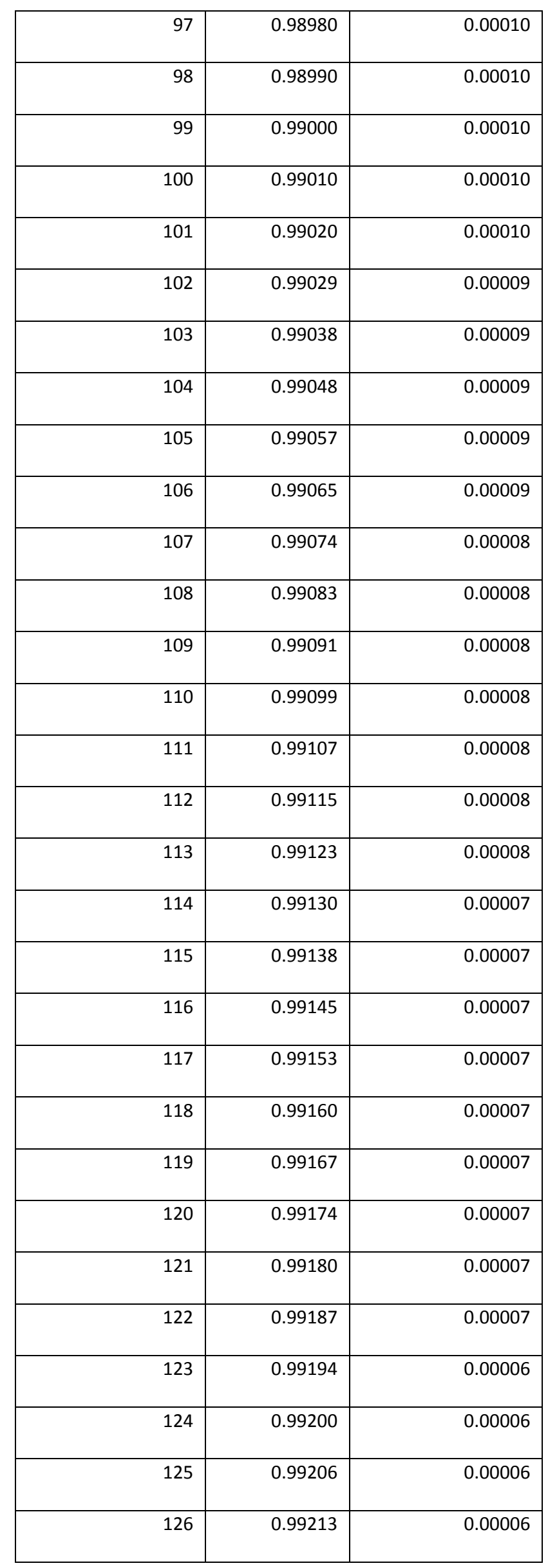




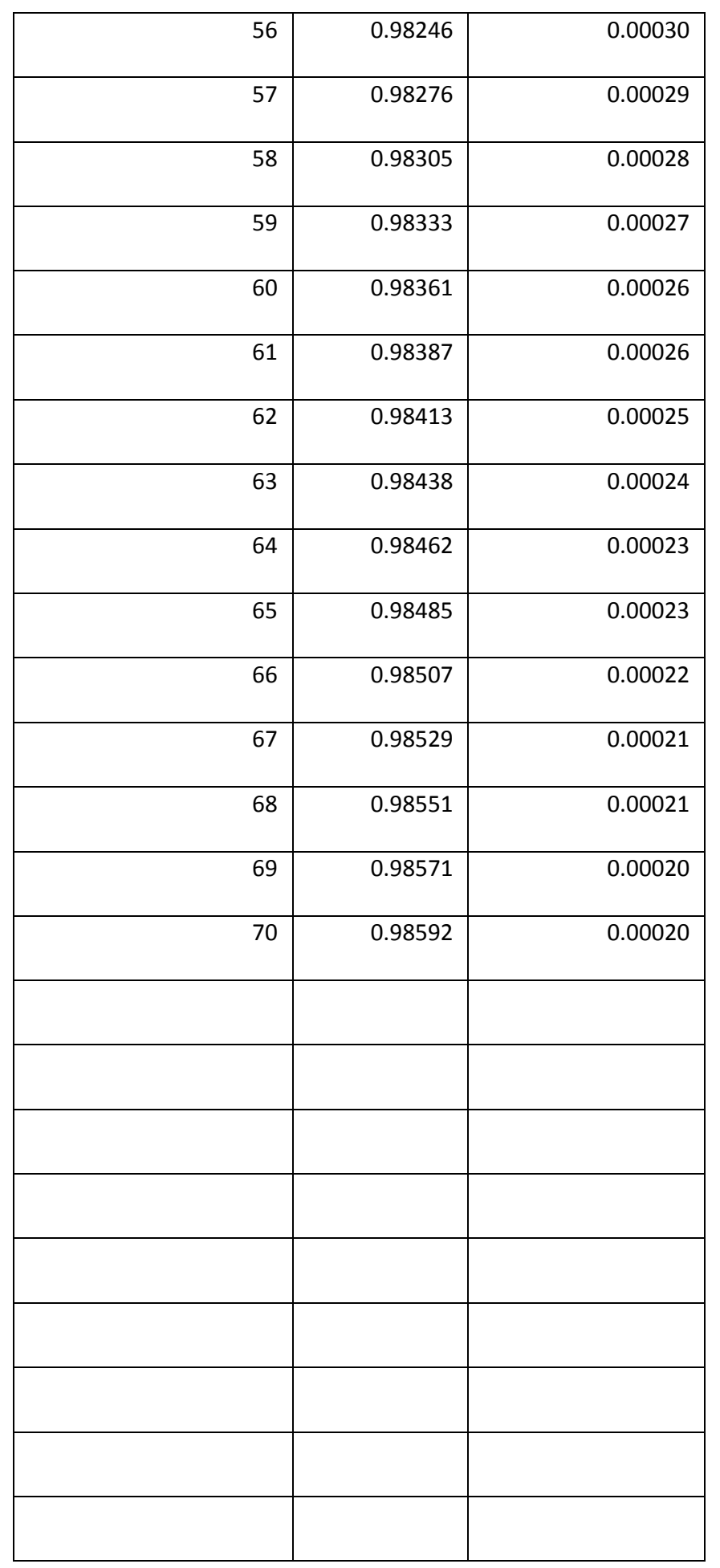

\begin{tabular}{|c|c|c|}
\hline 127 & 0.99219 & 0.00006 \\
\hline 128 & 0.99225 & 0.00006 \\
\hline 129 & 0.99231 & 0.00006 \\
\hline 130 & 0.99237 & 0.00006 \\
\hline 131 & 0.99242 & 0.00006 \\
\hline 132 & 0.99248 & 0.00006 \\
\hline 133 & 0.99254 & 0.00006 \\
\hline 134 & 0.99259 & 0.00005 \\
\hline 135 & 0.99265 & 0.00005 \\
\hline 136 & 0.99270 & 0.00005 \\
\hline 137 & 0.99275 & 0.00005 \\
\hline 138 & 0.99281 & 0.00005 \\
\hline 139 & 0.99286 & 0.00005 \\
\hline 140 & 0.99291 & 0.00005 \\
\hline 141 & 0.99296 & 0.00005 \\
\hline 142 & 0.99301 & 0.00005 \\
\hline 143 & 0.99306 & 0.00005 \\
\hline 144 & 0.99310 & 0.00005 \\
\hline 145 & 0.99315 & 0.00005 \\
\hline 146 & 0.99320 & 0.00005 \\
\hline 147 & 0.99324 & 0.00005 \\
\hline 148 & 0.99329 & 0.00004 \\
\hline 149 & 0.99333 & 0.00004 \\
\hline 150 & 0.99338 & - \\
\hline
\end{tabular}


Table B: Income from private account

\begin{tabular}{|c|c|c|c|}
\hline $\begin{array}{l}\text { Total contribution } \\
\text { to the private } \\
\text { account in LD }\end{array}$ & $\begin{array}{l}\text { Your income } \\
\text { from the private } \\
\text { account in LD }\end{array}$ & $\begin{array}{l}\text { Change of income if the total } \\
\text { contribution to your private } \\
\text { account increases by one unit }\end{array}$ & $\begin{array}{l}\text { Change of income if one } \\
\text { more unit is invested in the } \\
\text { joint project }\end{array}$ \\
\hline 0 & $\begin{array}{r}0.00 \\
\end{array}$ & 4.95 & 1.00 \\
\hline 1 & 4.95 & 4.85 & 1.00 \\
\hline 2 & 9.80 & 4.75 & 1.00 \\
\hline 3 & 14.55 & 4.65 & 1.00 \\
\hline 4 & 19.20 & 4.55 & 1.00 \\
\hline 5 & 23.75 & 4.45 & 1.00 \\
\hline 6 & 28.20 & 4.35 & 1.00 \\
\hline 7 & 32.55 & 4.25 & 1.00 \\
\hline 8 & 36.80 & 4.15 & 1.00 \\
\hline 9 & 40.95 & 4.05 & 1.00 \\
\hline 10 & 45.00 & 3.95 & 1.00 \\
\hline 11 & 48.95 & 3.85 & 1.00 \\
\hline 12 & 52.80 & 3.75 & 1.00 \\
\hline 13 & 56.55 & 3.65 & 1.00 \\
\hline 14 & 60.20 & 3.55 & 1.00 \\
\hline 15 & 63.75 & 3.45 & 1.00 \\
\hline 16 & 67.20 & 3.35 & 1.00 \\
\hline 17 & 70.55 & 3.25 & 1.00 \\
\hline 18 & 73.80 & 3.15 & 1.00 \\
\hline 19 & 76.95 & 3.05 & 1.00 \\
\hline 20 & 80.00 & 2.95 & 1.00 \\
\hline 21 & 82.95 & 2.85 & 1.00 \\
\hline 22 & 85.80 & 2.75 & 1.00 \\
\hline 23 & 88.55 & 2.65 & 1.00 \\
\hline 24 & 91.20 & 2.55 & 1.00 \\
\hline 25 & 93.75 & 2.45 & 1.00 \\
\hline 26 & 96.20 & 2.35 & 1.00 \\
\hline 27 & 98.55 & 2.25 & 1.00 \\
\hline 28 & 100.80 & 2.15 & 1.00 \\
\hline 29 & 102.95 & 2.05 & 1.00 \\
\hline 30 & 105.00 & 1.95 & 1.00 \\
\hline 31 & 106.95 & 1.85 & 1.00 \\
\hline 32 & 108.80 & 1.75 & 1.00 \\
\hline 33 & 110.55 & 1.65 & 1.00 \\
\hline 34 & 112.20 & 1.55 & 1.00 \\
\hline 35 & 113.75 & 1.45 & 1.00 \\
\hline 36 & 115.20 & 1.35 & 1.00 \\
\hline 37 & 116.55 & 1.25 & 1.00 \\
\hline 38 & 117.80 & 1.15 & 1.00 \\
\hline 39 & 118.95 & 1.05 & 1.00 \\
\hline 40 & 120.00 & 0.95 & 1.00 \\
\hline 41 & 120.95 & 0.85 & 1.00 \\
\hline 42 & 121.80 & 0.75 & 1.00 \\
\hline 43 & 122.55 & 0.65 & 1.00 \\
\hline 44 & 123.20 & 0.55 & 1.00 \\
\hline 45 & 123.75 & 0.45 & 1.00 \\
\hline 46 & 124.20 & 0.35 & 1.00 \\
\hline 47 & 124.55 & 0.25 & 1.00 \\
\hline 48 & 124.80 & 0.15 & 1.00 \\
\hline 49 & 124.95 & 0.05 & 1.00 \\
\hline 50 & 125.00 & -0.05 & 1.00 \\
\hline
\end{tabular}




\section{A5: Z-tree Screenshots}

Figure 8: Z-tree screenshot of $1^{\text {st }}$ stage decision on investment to the enforcement parameter

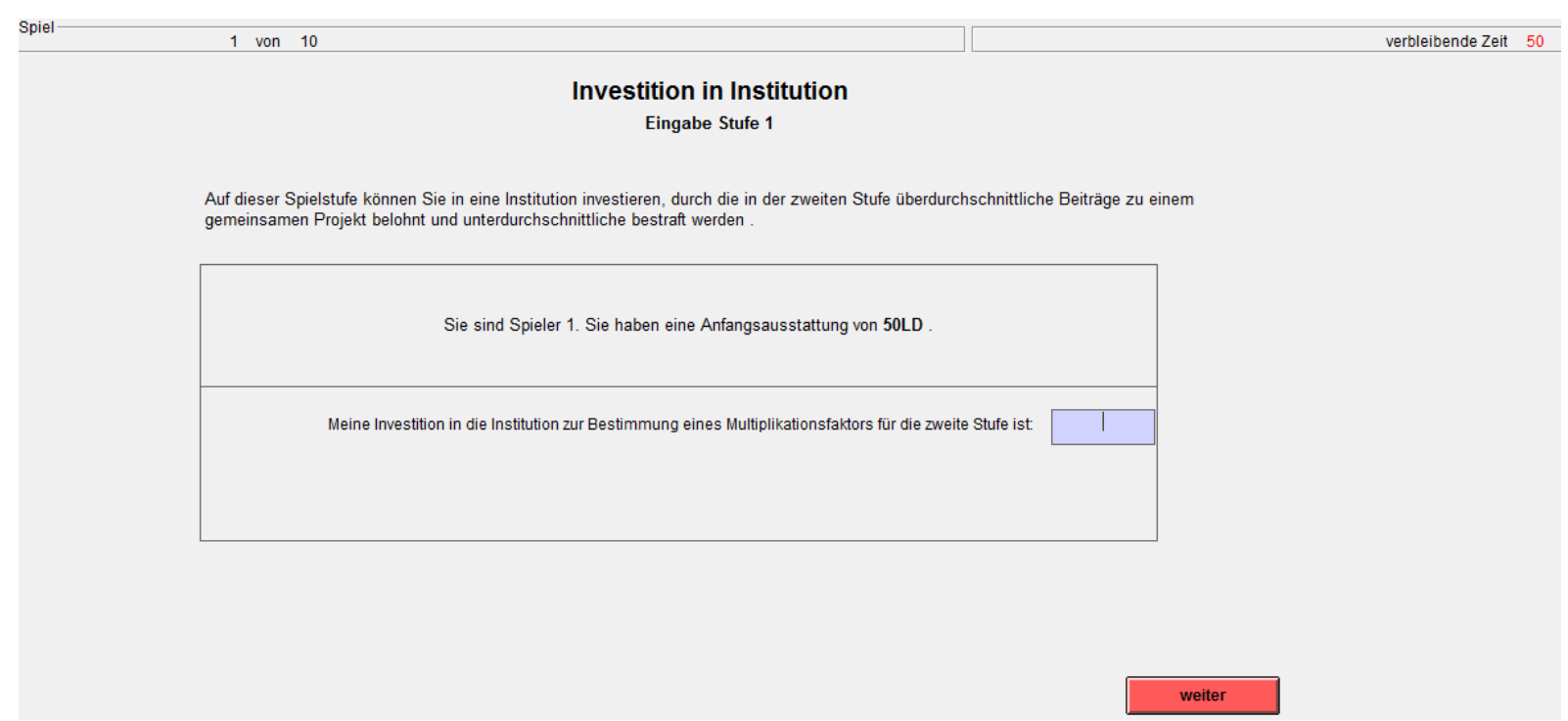

Figure 9: Z-tree screenshot of $2^{\text {nd }}$ stage decision on contribution to the public good

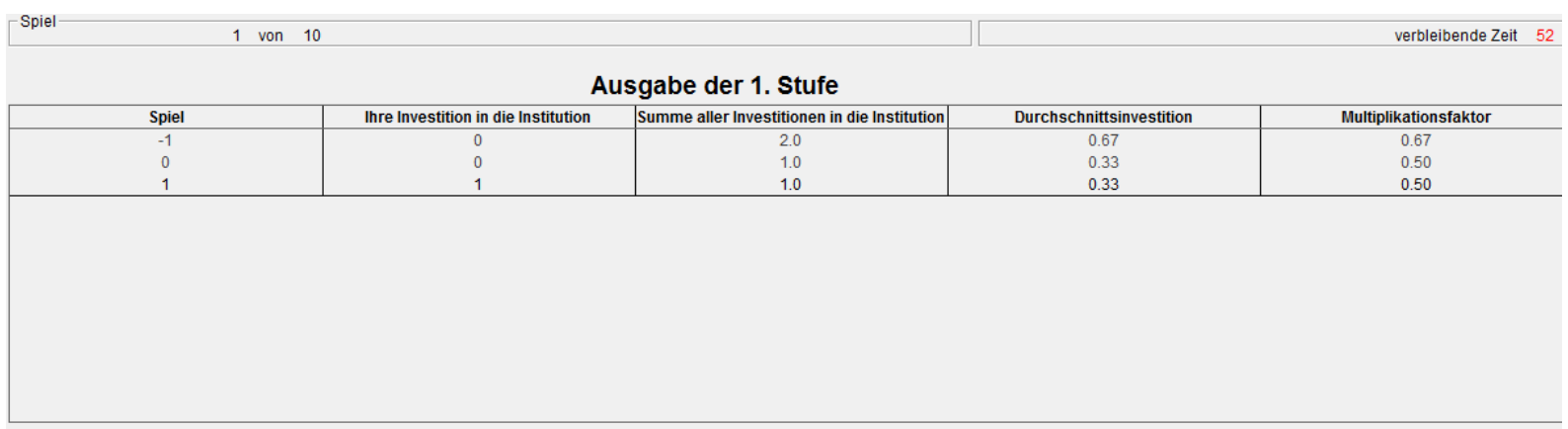

Beitragsentscheidung zum gemeinsamen Projekt der 2. Stufe

Eingabe der 2. Stufe

\begin{tabular}{|c|c|}
\hline & \multicolumn{2}{c|}{ Sie sind Spieler 1.} \\
\hline Sie haben eine Restausstattung in LD in Höhe von & 49.00 \\
\hline Mein Beitrag zum gemeinsamen Projekt ist & 1 \\
\hline
\end{tabular}

Welchen Durschnittsbeitrag der anderen beiden Gruppenmitglieder zum gemeinsamen Projekt erwarten Sie? 
Figure 10: Z-tree screenshot of the payoff composition of player 1 after the first period

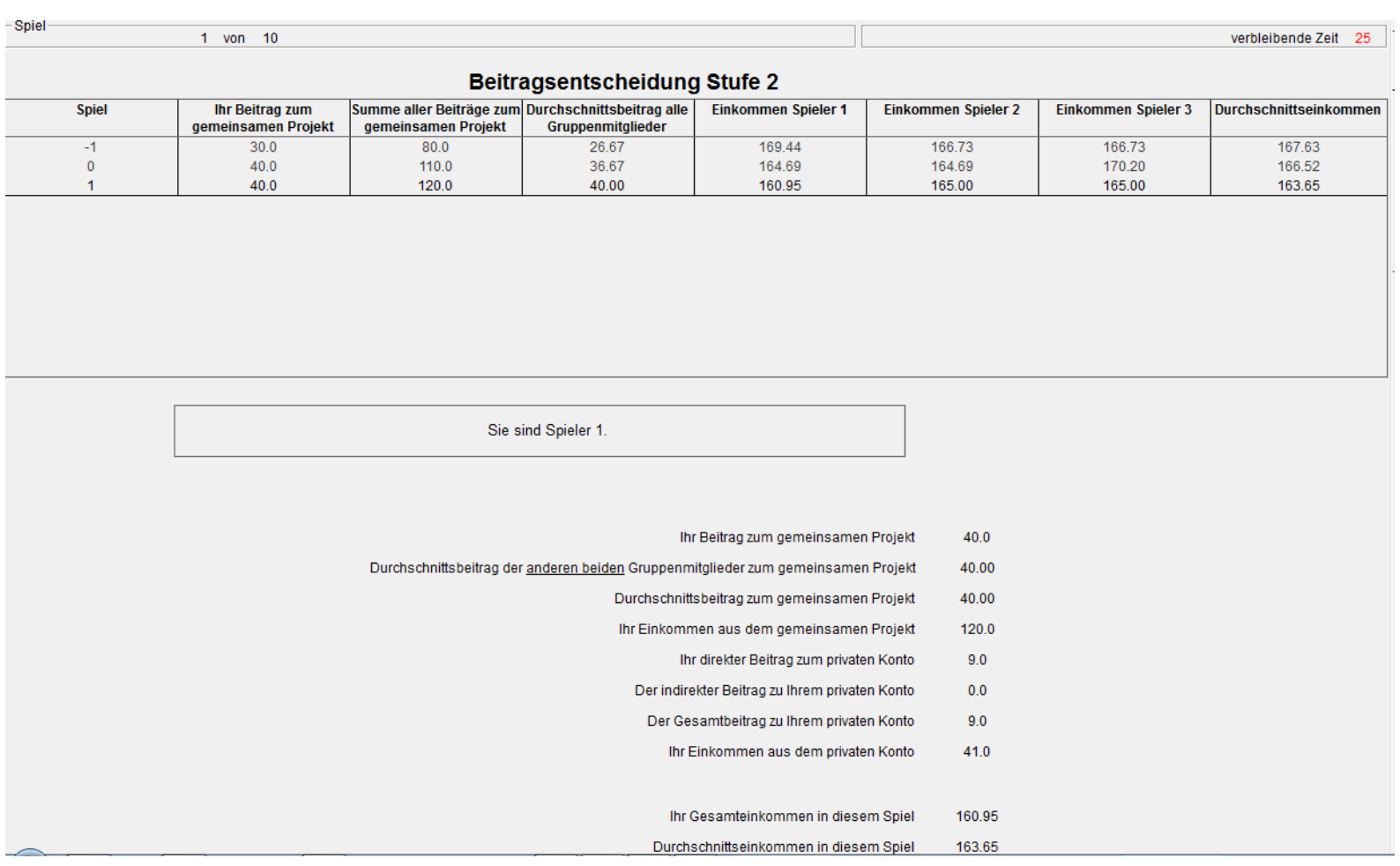

